\title{
Elevated H2AX Phosphorylation Observed with kINPen Plasma Treatment Is Not Caused by ROS-Mediated DNA Damage but Is the Consequence of Apoptosis
}

\author{
Sander Bekeschus $\mathbb{D}^{1}{ }^{1}$ Clarissa S. Schütz, ${ }^{1,2}$ Felix Nießner, ${ }^{1}$ Kristian Wende $\mathbb{D}^{1}{ }^{1}$ \\ Klaus-Dieter Weltmann, ${ }^{1}$ Nadine Gelbrich, ${ }^{2}$ Thomas von Woedtke, ${ }^{1,3}$ Anke Schmidt, \\ and Matthias B. Stope $\mathbb{D}^{2}$ \\ ${ }^{1}$ ZIK plasmatis, Leibniz Institute for Plasma Science and Technology (INP Greifswald), Greifswald, Germany \\ ${ }^{2}$ Department of Urology, Greifswald University Medical Center, Greifswald, Germany \\ ${ }^{3}$ Institute for Hygiene and Environmental Medicine, Greifswald University Medical Center, Greifswald, Germany \\ Correspondence should be addressed to Sander Bekeschus; sander.bekeschus@inp-greifswald.de
}

Received 24 May 2019; Revised 23 July 2019; Accepted 26 August 2019; Published 19 September 2019

Guest Editor: Rizwan Wahab

Copyright (c) 2019 Sander Bekeschus et al. This is an open access article distributed under the Creative Commons Attribution License, which permits unrestricted use, distribution, and reproduction in any medium, provided the original work is properly cited.

\begin{abstract}
Phosphorylated histone 2AX ( $\gamma \mathrm{H} 2 \mathrm{AX})$ is a long-standing marker for DNA double-strand breaks (DSBs) from ionizing radiation in the field of radiobiology. This led to the perception of $\gamma \mathrm{H} 2 \mathrm{AX}$ being a general marker of direct DNA damage with the treatment of other agents such as low-dose exogenous ROS that unlikely act on cellular DNA directly. Cold physical plasma confers biomedical effects majorly via release of reactive oxygen and nitrogen species (ROS). In vitro, increase of $\gamma \mathrm{H} 2 \mathrm{AX}$ has often been observed with plasma treatment, leading to the conclusion that DNA damage is a direct consequence of plasma exposure. However, increase in $\gamma \mathrm{H} 2 \mathrm{AX}$ also occurs during apoptosis, which is often observed with plasma treatment as well. Moreover, it must be questioned if plasma-derived ROS can reach into the nucleus and still be reactive enough to damage DNA directly. We investigated $\gamma \mathrm{H} 2 \mathrm{AX}$ induction in a lymphocyte cell line upon ROS exposure (plasma, hydrogen peroxide, or hypochlorous acid) or UV-B light. Cytotoxicity and $\gamma \mathrm{H} 2 \mathrm{AX}$ induction was abrogated by the use of antioxidants with all types of ROS treatment but not UV radiation. H2AX phosphorylation levels were overall independent of analyzing either all nucleated cells or segmenting $\gamma \mathrm{H} 2 \mathrm{AX}$ phosphorylation for each cell cycle phase. SB202190 (p38-MAPK inhibitor) and Z-VAD-FMK (pan-caspase inhibitor) significantly inhibited $\gamma \mathrm{H} 2 \mathrm{AX}$ induction upon ROS but not UV treatment. Finally, and despite $\gamma \mathrm{H} 2 \mathrm{AX}$ induction, UV but not plasma treatment led to significantly increased micronucleus formation, which is a functional read-out of genotoxic DNA DSBs. We conclude that plasma-mediated and low-ROS $\gamma \mathrm{H} 2 \mathrm{AX}$ induction depends on caspase activation and hence is not the cause but consequence of apoptosis induction. Moreover, we could not identify lasting mutagenic effects with plasma treatment despite phosphorylation of H2AX.
\end{abstract}

\section{Introduction}

$\gamma \mathrm{H} 2 \mathrm{AX}$ is a recognized marker for DNA double-strand breaks (DSBs) in radiation biology [1]. Phosphorylation at serine139 of the histone $2 \mathrm{AX}$ occurs rapidly, and approximately $1 \%$ of all $\mathrm{H} 2 \mathrm{AX}$ proteins are phosphorylated per gray irradiation via a molecular machinery [2]. Based on these findings in radiobiology, $\gamma \mathrm{H} 2 \mathrm{AX}$ has been used as direct surrogate and correlate of DNA DSBs in a variety of studies test- ing chemical and physical treatments, for example, in the field of oncology [3]. One novel physical treatment modality for the treatment of cancer is cold physical plasma [4]. Its antitumor effects on several types of tumor cells such as skin cancer have been shown in vitro and in vivo [5-7], and to a limited extent also in small patient cohorts [8]. Medical plasmas are multicomponent systems consisting of, e.g., electrons and ions, electric fields, and a multiplicity of different reactive oxygen and nitrogen species (ROS) [9]. 
ROS are the major component mediating biomedical effects of plasma treatment, at least in vitro [10-12]. Concomitant with plasma-induced cell death, many studies reported a phosphorylation of $\mathrm{H} 2 \mathrm{AX}$ with different kinds of plasma sources and (tumor) cell types [13-19]. This lead to the conclusion that plasma-derived ROS directly induce DNA damage. Yet, there are several pitfalls of this assumption. Firstly, plasma-derived ROS are not generated within the cells but reach them from the outside. Due to the charge as well as short lifetime of some of these species detected and quantified in plasma-treated liquids, and hence possibly in the vicinity of cells [20-22], only a fraction of the ROS is able to diffuse or being transported through the cell membrane directly. Secondly, once in the cytosol, there are abundant reaction partners including, for instance, peroxiredoxins (PRDX) to scavenge the ROS [23]. Thirdly, the remaining ROS would have to cross several membranes of the endoplasmic reticulum (ER) and ultimately the nucleus membrane to directly act on cellular DNA after-again-passing by several antioxidant proteins such as PRDX2 [24]. In the light of large distances $(2-10 \mu \mathrm{m})$ that ROS would have to travel from the membrane to the nucleus, the direct action of plasma-derived ROS on cellular DNA denies the nature of ROS being reactive and short-lived. This also questions the conclusion that $\gamma \mathrm{H} 2 \mathrm{AX}$ is an indicator of DNA DSBs arising from primary ROS derived from plasma treatment. Rather, a role of $\gamma \mathrm{H} 2 \mathrm{AX}$ might be in marking DNA DSBs secondary to plasma treatment (e.g., due to apoptosis). $\gamma \mathrm{H} 2 \mathrm{AX}$ was originally identified as an early event after the direct formation of DSBs. Now, $\gamma$-H2AX is considered to occur after the indirect formation of DSBs caused by cellular process such as DNA repair, replication, and/or transcription at sites of initial DNA damage such as oxidative bases, DNA adducts, single-strand breaks, cross-linking, and DNA photoproducts $[25,26]$.

In general, $\gamma \mathrm{H} 2 \mathrm{AX}$ seems to fulfill pleiotropic roles in cell biology. For instance, low levels of $\gamma \mathrm{H} 2 \mathrm{AX}$ are not associated with DNA DSBs [27]. Untreated cells are found to be positive for $\gamma \mathrm{H} 2 \mathrm{AX}$ in the $\mathrm{M}$ phase of the cell cycle without being exposed to a DNA-damaging agent [28]. Decreased expression of the H2AX primarily leads to damage in the mitochondria [29]. The amount of $\gamma \mathrm{H} 2 \mathrm{AX}$ in apoptotic cells also exceeds that of nonapoptotic cells by a factor of ten [30]. $\gamma \mathrm{H} 2 \mathrm{AX}$ also seems dispensable for the initial recognition of DNA breaks [31]. Finally, there is evidence that not only DNA DSBs but also ROS may be responsible for $\gamma \mathrm{H} 2 \mathrm{AX}$ induction [32]. Mechanistically, it is known that while the serine/threonine kinase ataxia telangiectasia mutated (ATM) forms $\gamma \mathrm{H} 2 \mathrm{AX}$ at DNA DSBs [33], the serine/threonine kinase ataxia telangiectasia and Rad3-related protein (ATR) have been also implicated in this process [34]. Interestingly, ATM does so by redox-sensitive thiols, so ATM activation is a marker of both oxidative stress and DNA DSBs [35].

In the light of these studies, we sought to study the role of plasma-derived ROS in $\gamma \mathrm{H} 2 \mathrm{AX}$ induction. The lymphocyte cell line TK6 was treated with an atmospheric pressure argon plasma jet (kINPen) as ROS-source. The $\gamma \mathrm{H} 2 \mathrm{AX}$ expression along with the amount of ROS, ROS scavengers, cell viability, and an OECD- (Organization for Economic Co-operation and Development-) accredited genotoxicity (micronucleus) assay were investigated. We found that plasma but not UVinduced $\gamma \mathrm{H} 2 \mathrm{AX}$ induction was dependent on apoptosis and caspase activation, making DNA damage marked via $\gamma \mathrm{H} 2 \mathrm{AX}$ rather a consequence than the cause for plasma-induced cell death.

\section{Materials and Methods}

2.1. Cell Culture. Lymphocytes are the cell type most often used when investigating DNA damage [36]. Especially the human TK6 lymphocyte cell line has been widely utilized in genotoxicity studies [37, 38]. For this reason, we used TK6 (ATCC CRL-8015) cells, a p53-competent, human lymphoblast cell line. Cells were cultured in Roswell Park Memorial Medium without phenol red (RPMI1640; PanBioTech) supplemented with $10 \%$ fetal bovine serum, $2 \%$ glutamine, and $1 \%$ penicillin/streptomycin (all Sigma). All incubations were performed in cell culture conditions (CB210; Binder) at $37^{\circ} \mathrm{C}, 95 \%$ humidity, and $5 \%$ carbon dioxide. As ROS scavengers, catalase (cat; $20 \mu \mathrm{g} / \mathrm{ml}$ ), glutathione (GSH; $1 \mathrm{mM}$ ), or superoxide dismutase (SOD; $100 \mathrm{U} / \mathrm{ml}$ ) was used (all Sigma). As enzyme or signaling inhibitors, Z-VAD-FMK (R\&D Biosciences), SB202190 (Sigma), KU55933 (SelleckChem), Ly294002 (Cell Signaling Technologies), wortmannin (InvivoGen), or SP600125 (Santa Cruz Biotechnology) was used at different concentrations and incubated with cells for $1 \mathrm{~h}$ prior ROS or UV treatment. Final concentrations for a selected choice of inhibitors were $1 \mu \mathrm{M}$ for KU55933, $1 \mu \mathrm{M}$ for SB202190, and $25 \mu \mathrm{M}$ for Z-VAD-FMK.

2.2. Exposure of Cells to ROS, Cold Physical Plasma, or UV. For all procedures, $2.5 \times 10^{5}$ TK6 cells in $500 \mu \mathrm{l}$ of fully supplemented cell culture medium were added to wells of a 24-well plate (Sarstedt). For hydrogen peroxide $\left(\mathrm{H}_{2} \mathrm{O}_{2}\right.$; Sigma) treatment, the stock was diluted in double-distilled water, and a range of concentrations was tested initially. Final concentration for subsequent assays was $10 \mu \mathrm{M}$. For hypochlorous acid ( $\mathrm{HOCl}$; Roth), the stock was diluted in double-distilled water, and a range of concentrations was tested initially. Final concentration for subsequent assays was $500 \mu \mathrm{M}$. Plasma treatment was done using the atmospheric pressure argon plasma jet kINPen (neoplas tools) that expels various reactive agents (Figure 1(a)) as reported before [9]. Its biomedical effects were summarized recently [39]. The plasma source was operated at two standard liters per minute of argon gas (Air Liquide, purity 99.999\%). Plasma treatment was performed in a highly standardized manner as shown previously [40]. Briefly, the plasma jet was attached to a computer-controlled $x y z$-table (CNC step), which hovered the plasma exactly over the center of each well for a predefined time and height. A range of treatment times was initially tested. Immediately after treatment, a predetermined amount of double-distilled water was added to the wells after plasma treatment to compensate for evaporation effects and to maintain isoosmolality. A treatment time of $10 \mathrm{~s}$ was used for subsequent experiments if not indicated otherwise. For exposure to UV light, a range of exposure 


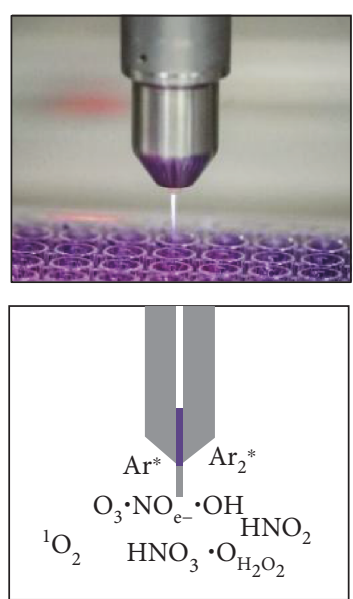

(a)

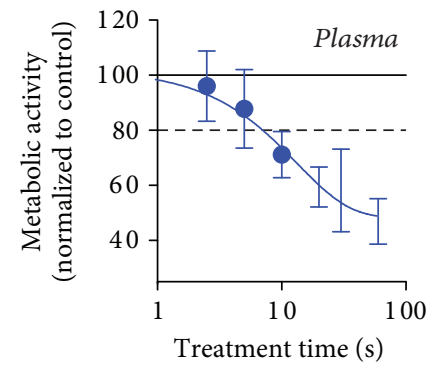

(b)

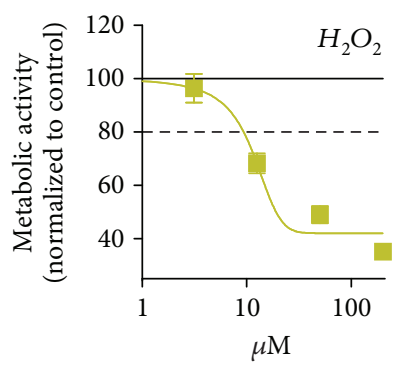

(c)

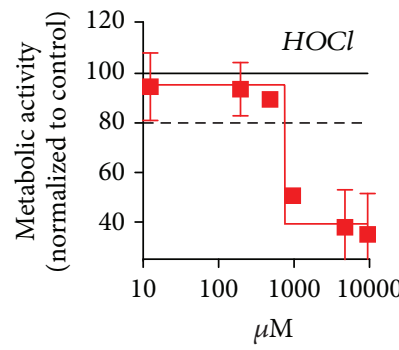

(d)

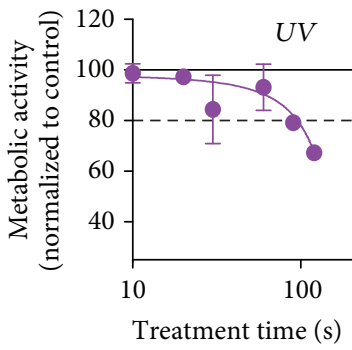

(e)

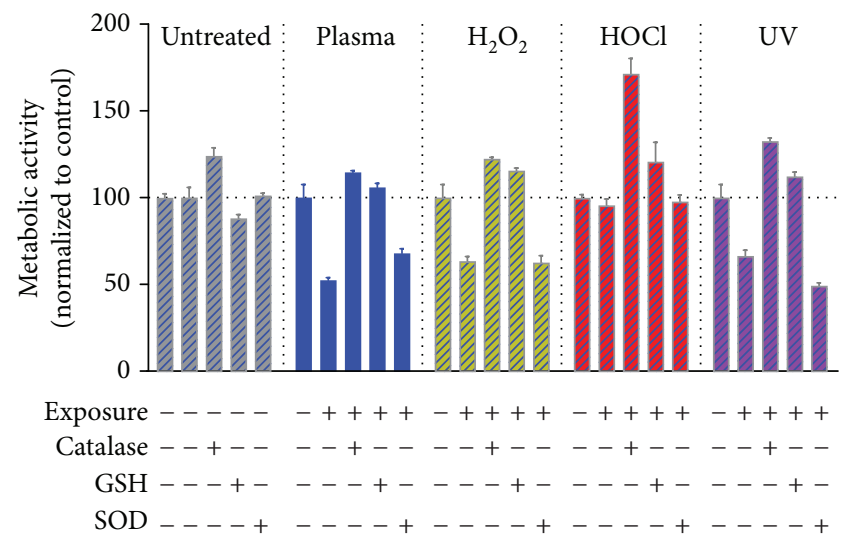

(f)

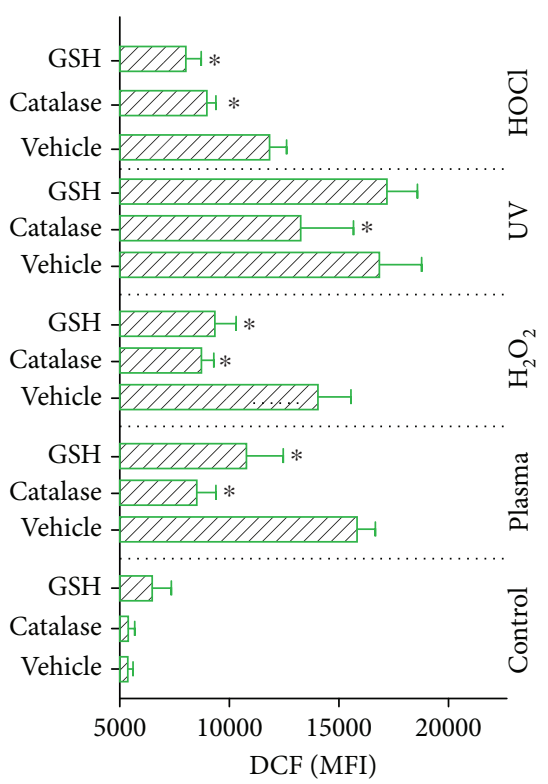

Control

Plasma

(g)

(h)

Figure 1: Continued. 


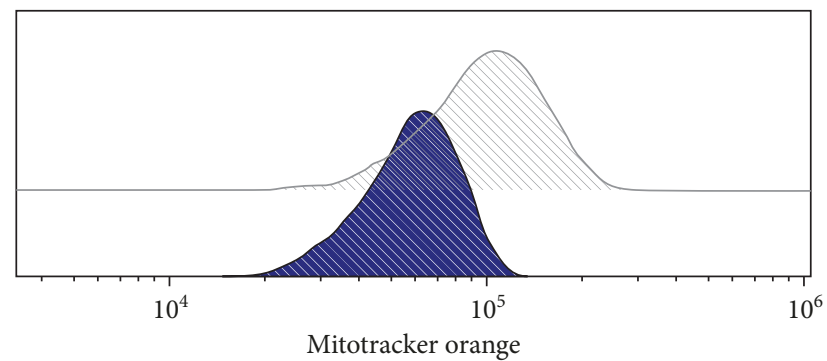

Control MTO control

Plasma MTO plasma

(i)

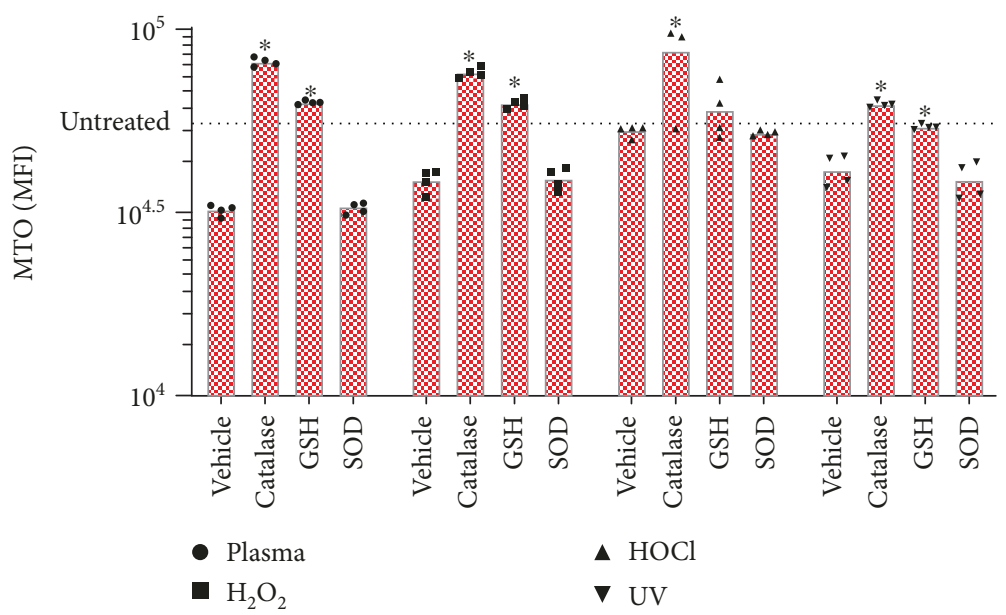

(j)

FIGURE 1: Metabolic activity and oxidation of TK6 cells after exposure to plasma, $\mathrm{H}_{2} \mathrm{O}_{2}, \mathrm{HOCl}$, and UV. (a) Image (top) and scheme (bottom) with some of the products generated by the kINPen argon plasma jet. (b-e) Metabolic activity $6 \mathrm{~h}$ after exposure to different concentrations of ROS, or plasma or UV treatment times. (f) Effects of antioxidants or ROS scavenging enzymes on the metabolic activity of cells in responses to treatments after $6 \mathrm{~h}$. (g) Overlay histogram of DCF fluorescence of control and plasma-treated cells. (h) Quantification of DCF fluorescence in cells immediately after treatment in the presence or absence of antioxidants. (i) Overlay histogram of mitotracker orange (MTO) in cells $6 \mathrm{~h}$ after plasma treatment. (j) Quantification of mitochondrial mass in cells exposed to various agents in the presence or absence of antioxidants. Data are mean + S.E. of 2-4 independent experiments with several replicates each. Statistical analysis $(h, j)$ within each treatment group was done with one-way ANOVA and Dunnett's post hoc test to vehicle control.

times was tested, and $120 \mathrm{~s}$ was used for experiments if not indicated otherwise. The wells of the plate that were not intended to be exposed to UV light were covered with aluminum foil. A broadband UVB (20-160 J $\mathrm{Jff}^{-2}$ ) light source (Philips TL12 fluorescent lamp) emitting radiation between 290 and $315 \mathrm{~nm}$ was used. UVB exposure modifies DNA directly by forming cyclobutane pyrimidine dimers (CPD) and 6-4 photoproducts. Indirect effects of UVB on DNA occur due to photolysis and generation of hydroxyl radicals, leading to formation of 8 -hydroxy- $2^{\prime}$-deoxyguanosine (8-OhdG) [41].

2.3. Intracellular Oxidation. To assess intracellular oxidation, TK6 cells were stained with chloromethyl $2^{\prime}, 7^{\prime}$-dichlorodihydrofluorescein diacetate $\left(\mathrm{CM}-\mathrm{H}_{2} \mathrm{DCF}-\mathrm{DA}\right.$; final concentration $2.5 \mu \mathrm{M}$; Thermo Fisher) in phosphate-buffered saline (PBS), washed, and resuspended in fully supplemented cell culture medium (in the presence or absence of antioxi- dants). Cells were seeded into plates and treated as described above. Immediately after, cells were added to $12 \times 75 \mathrm{~mm}$ tubes (Sarstedt) containing $4^{\prime}, 6$-diamidin-2-phenylindol (DAPI; final concentration $1 \mu \mathrm{M}$; Sigma), and samples were acquired by multicolor flow cytometry (Gallios, equipped with 405 nm, $488 \mathrm{~nm}$, and 638 nm laser; Beckman Coulter). Sample analysis was performed using Kaluza 2.1.1 software (Beckman Coulter) and analyzing the mean fluorescent intensity (MFI) of DCF within the viable (DAPI-) cell fraction.

2.4. Metabolic Activity, Mitochondrial Mass, and Viability. Metabolic activity was investigated by incubating the cells for $4 \mathrm{~h}$ with resazurin (final concentration $100 \mu \mathrm{M}$; Alfa Aesar) after two hours of incubation posttreatment. Metabolically active cells transform nonfluorescent resazurin into fluorescent resorufin, which can be quantified using a multiplate reader (F200; Tecan) at $\lambda_{\mathrm{ex}} 560 \mathrm{~nm}$ and $\lambda_{\mathrm{em}} 590 \mathrm{~nm}$. Absolute sample values were normalized to that of untreated 
cells $=100 \%$. To quantify mitochondrial mass, cells were incubated for $15 \mathrm{~min}$ with chloromethyltetramethylrosamine, also called MitoTracker Orange (MTO; final concentration $1 \mu \mathrm{M}$; Thermo Fisher), at $6 \mathrm{~h}$ after plasma treatment. The cationic rosamine probe only binds to mitochondrial membranes with intact potential. Sample acquisition was performed using flow cytometry. To quantify nonterminally dead (alive) and terminally dead cells, DAPI was used to discriminate the percentage of either population using flow cytometry. For some experiments, the amount of cells active for caspase 3 and 7 was investigated to quantify the amount of apoptotic cells. For this, cells were incubated for $30 \mathrm{~min}$ with Cellevent dye (final concentration $2.5 \mu \mathrm{M}$; Thermo Fisher). Samples were analyzed by flow cytometry.

2.5. Analysis of Cell Cycle and $\gamma H 2 A X$. Flow cytometry is the most sensitive, quantitative, and informative method of analyzing and quantifying $\gamma \mathrm{H} 2 \mathrm{AX}$ in cells, as it can be related to cell cycle and other cellular populations stained with additional markers [36]. To prepare the cells for DNA and $\gamma \mathrm{H} 2 \mathrm{AX}$ staining, cells were harvested $2 \mathrm{~h}$ after exposure to agents into $12 \times 75 \mathrm{~mm}$ tubes. In an initial kinetic experiment, $2 \mathrm{~h}$ was shown to be optimal. Cells were washed with PBS and fixed with $-20^{\circ} \mathrm{C}$ methanol for $30 \mathrm{~min}$ at $4^{\circ} \mathrm{C}$. Cells were washed and incubated with murine phosphor-specific anti- $\gamma \mathrm{H} 2 \mathrm{AX}$ antibodies (BioLegend) for $20 \mathrm{~min}$. The optimal antibody dilution was determined experimentally. Cells were washed and incubated with DAPI $(10 \mu \mathrm{M})$ and an antimouse IgG1 antibody conjugated to Alexa Fluor 647 (Thermo Fisher) for $20 \mathrm{~min}$ in permeabilization wash buffer (BioLegend) in the dark. Cells were washed and resuspended in PBS and acquired by flow cytometry. Gating of cells was performed as shown. Appropriate gating of the DAPI-area vs. DAPI-width parameters for cell cycle analysis was confirmed with Michael H. Fox algorithm integrated into Kaluza analysis software. If the algorithm could not calculate G1, S, and G2 phase properly, the gating was adjusted accordingly. This way, $\gamma \mathrm{H} 2 \mathrm{AX}$ induction could be accurately calculated in relation to mathematical modeling for each cell cycle phase. A total of more than 1.800 single FACS measurements was prepared, stained, and individually acquired in this study. Each measurement contained at least 20,000 single cells, yielding quantitative single cell data. To analyze $\gamma \mathrm{H} 2 \mathrm{AX}$ foci via laser scanning confocal microscopy (TP5; Leica), cells were stained as described above and added to 8-well glass slides (Ibidi). Fluorescence was acquired using excitation at $405 \mathrm{~nm}$ for DAPI and $640 \mathrm{~nm}$ for Alexa Fluor 647.

2.6. Quantification of Micronuclei. The cytokinesis-block micronucleus (MN) assay requires quantification of micronuclei in binucleated cells (BNCs) only [42]. Cells were treated as described above with minor changes and incubated for $24 \mathrm{~h}$. As additional genotoxic positive control, the DNAdamaging agent methyl methanesulfonate (MMS; final concentration $20 \mathrm{ng} / \mathrm{ml}$; Sigma) was added. The plasma treatment time was reduced from $10 \mathrm{~s}$ to $2.5 \mathrm{~s}$ as the plasma treatment acted synergistically toxic together with cytochalasin B, leading to insufficient cell counts. Similar observations were made for UV treatment, which was reduced from $120 \mathrm{~s}$ to
$24 \mathrm{~s}$. Ten wells were pooled into T75 flasks (Sarstedt) per condition, and cytochalasin B (final concentration $5 \mu \mathrm{g} / \mathrm{ml}$; Sigma) was added. Flasks were incubated for another $24 \mathrm{~h}$. Cells were collected into $15 \mathrm{ml}$ tubes (Sarstedt), washed, fixed with $4 \%$ fixation buffer (BioLegend) for $20 \mathrm{~min}$, and washed and stored at $4^{\circ} \mathrm{C}$ in PBS until staining. For staining, cells were washed and stained in permeabilization wash buffer (BioLegend) containing draq5 (final concentration $50 \mu \mathrm{M}$; BioLegend) for $20 \mathrm{~min}$ at room temperature in the dark. Other DNA staining dyes were also compared (SYTOX green, final concentration $1 \mu \mathrm{M}$, Thermo Fisher; DAPI, final concentration $10 \mu \mathrm{M}$, Sigma; Hoechst 33342, final concentration $10 \mu \mathrm{g} / \mathrm{ml}$, Sigma) but found to be less suitable. Cells were washed in permeabilization wash buffer and resuspended in PBS in siliconized $1.5 \mathrm{ml}$ tubes. Speed beats (Merck Millipore) were used to operate the imaging fluids of an ImageStream ISX Mark II (Merck Millipore), which was used for sample acquisition. Up to $2 \times 10^{5}$ cells (images) were acquired per sample. The digital $\mathrm{MN}$ analysis was in main parts similar as reported before [43], with some minor modifications in mask design and gating steps. A total of more than 40 Mio single cells-each represented by at least two individual images of about $200 \times 200$ pixels in size-were acquired and partly analyzed in this study.

2.7. Statistical Analysis. Data were analyzed and graphed using Prism 8.1 (GraphPad software). Mean and standard error (S.E.) were given if not indicated otherwise. Statistical analysis was performed either using one-way analysis of variances or $t$-test.

\section{Results}

3.1. Viability and Oxidation upon Exposure to Plasma, $\mathrm{H}_{2} \mathrm{O}_{2}$, $\mathrm{HOCl}$, and UV Light. In order to obtain ROS concentrations and UV exposure times as well as plasma treatment times that were neither too toxic nor failed to show effects on cells, dilution and treatment time series were performed, respectively. From these, we concluded to use $10 \mathrm{~s}$ of plasma treatment (Figure 1(b)), $10 \mu \mathrm{M}$ of $\mathrm{H}_{2} \mathrm{O}_{2}$ (Figure 1(c)), $500 \mu \mathrm{M}$ of $\mathrm{HOCl}$ (Figure 1(d)), and $120 \mathrm{~s}$ of UV treatment (Figure $1(\mathrm{e})$ ) in viability experiments assayed $6 \mathrm{~h}$ after exposure for subsequent experiments. Data for metabolic activity were in principal similar for longer incubation times (Supplementary Figure S1a). Terminally dead cells at $6 \mathrm{~h}$ posttreatment were also quantified (Supplementary Figure S1b). Next, it was tested whether antioxidant agents and enzymes protected cells $6 \mathrm{~h}$ postagent-induced toxicity (Figure 1(f)). While catalase (cat) and glutathione (GSH) conferred protection, superoxide dismutase (SOD) did not. To confirm that this finding was related to protection from ROS, cells were stained with $\mathrm{CM}-\mathrm{H}_{2} \mathrm{DCF}-$ DA, which after intracellular modifications fluoresces upon oxidation with, e.g., plasma treatment (Figure 1(g)). Indeed, GSH and cat significantly protected cells from oxidation with plasma, $\mathrm{H}_{2} \mathrm{O}_{2}$, and $\mathrm{HOCl}$ treatment (Figure $1(\mathrm{~h})$ ). For UV exposure, only cat but not GSH conferred protection. This might be due to UV radiation directly oxidizing DCFH-DA. In lymphocytes, ROS-induced toxicity leads 
to depolarization of the mitochondrial membrane potential $\Delta \Psi \mathrm{m}[44]$, which allows the quantification of mitochondria with intact $\Delta \Psi \mathrm{m}$ using appropriate dyes (Figure 1(i)). The agents decreased the total amount of mitochondria with intact $\Delta \Psi \mathrm{m}$, while cat and GSH but not SOD protected from insult (Figure 1(j)). Presence of cat even led to higher values, suggesting the growth-supporting activity of antioxidant enzymes. In summary, the ROS agents and UV radiation oxidized the cells leading to mitochondrial damage and reduction of metabolic activity and viability.

3.2. Induction of $\gamma H 2 A X$ Depended on ROS but Not of Cell Cycle Phase. To quantify $\gamma \mathrm{H} 2 \mathrm{AX}$ in cells, a rigid flow cytometric gating strategy was set up. Cells were gated based on time (Figure 2(a)) and forward and side scatter properties (Figure 2(b)) followed by exclusion of doublets, aggregates, and subG1 cells (Figure 2(c)). $\gamma \mathrm{H} 2 \mathrm{AX}$ was quantified in singlets (Figure $2(\mathrm{~d})$ ). Alternatively, $\gamma \mathrm{H} 2 \mathrm{AX}$ was determined per cell cycle phase, which was validated using Michael H. Fox algorithms (Figure 2(e)). For each phase, a separate gating was applied (Figure 2(f)), from which the number (\% gated) and intensity (mean fluorescence intensity of $\%$ gated) was calculated (Figure 2(g)). Staining was performed using appropriate antibody dilutions (Supplementary Figure S1c) at $2 \mathrm{~h}$ posttreatment (Supplementary Figure S1d) and was confirmed using confocal laser scanning microscopy (Figure 2(h)). $\gamma \mathrm{H} 2 \mathrm{AX}$ foci are formed within seconds, but since they are initially quite small, reliably quantification is recommend earliest at $30 \mathrm{~min}$ after initial insult [45]. A prominent $\gamma \mathrm{H} 2 \mathrm{AX}$ induction was observed with plasma and UV treatment and to a lesser extent with $\mathrm{H}_{2} \mathrm{O}_{2}$ and $\mathrm{HOCl}$ exposure (Figure 2(i)). This difference may be explained by slight $\left(\mathrm{H}_{2} \mathrm{O}_{2}\right)$ and larger $(\mathrm{HOCl})$ differences of the oxidants to induce cytotoxic effects as compared to those seen with plasma (Figures $1(\mathrm{f})$ and $1(\mathrm{j})$ ). The reason might have been a change of TK6 sensitivity between the initial titration (Figures 1(b) and 1(c)) and subsequent experiment due to passage number. Strikingly, antioxidants (GSH and cat) significantly reduced $\gamma \mathrm{H} 2 \mathrm{AX}$ induction for plasma and $\mathrm{H}_{2} \mathrm{O}_{2}$ treatment. For UV treatment, it was significantly enhanced. Similar observations were made when analyzing $\gamma \mathrm{H} 2 \mathrm{AX}$ induction for each phase of the cell cycle (Figure 2(j)). In general, G1 cells gave lower signals compared to $\mathrm{S}$ and $\mathrm{G} 2$ phase cells, and the increase observed with antioxidants in UV conditions was evenly proportional for each cell cycle phase. Notably, cat and GSH had no effect on $\gamma \mathrm{H} 2 \mathrm{AX}$ induction in resting (untreated) cells for each cell cycle phase (Supplementary Figure S1e). By contrast, the antioxidant $\mathrm{N}$-acetylcysteine (NAC) increased $\gamma \mathrm{H} 2 \mathrm{AX}$ induction in untreated as well as treated cells (Supplementary Figure S1f). With reference to cell cycle phase-dependent $\gamma \mathrm{H} 2 \mathrm{AX}$ intensity (Figure $2(\mathrm{j})$ ), another question was whether there was a relatively higher increase in proliferating ( $\mathrm{S}$ and G2 phase) cells. These cells have intrinsically more DSBs and unwinded DNA, which could make them more prone to ROS-induced DNA damage. It was observed that the opposite was the case, as $\gamma \mathrm{H} 2 \mathrm{AX}$ intensity in $\mathrm{S}$ over G1 and G2 over G1 was overall significantly lower compared to those of untreated control cells (Supplementary Figure 1g). Altogether, $\gamma \mathrm{H} 2 \mathrm{AX}$ showed a major increase in plasma-treated cells, which was almost fully abrogated in presence of cat or GSH during the treatment.

3.3. Intracellular Signaling and Apoptosis Govern PlasmaInduced $\gamma H 2 A X$. The next question was to investigate intracellular signaling events upon plasma-induced H2AX phosphorylation. Many pathways leading to $\gamma \mathrm{H} 2 \mathrm{AX}$ have been unraveled [36], and we used several inhibitors in preliminary tests (Supplementary Figure S2a-f). One promising candidate was SB202190, a p38-MAPK inhibitor, which gave a significant decrease in $\gamma \mathrm{H} 2 \mathrm{AX}$ induction for all ROS but not for UV treatment (Figure 3(a)). Similar results were achieved with Z-VAD-FMK, a pan-caspase inhibitor (Figure 3(b)), but only a no-significant reduction was observed with KU59933 for plasma conditions (Supplementary Figure 2g), an ataxia telangiectasia mutated (ATM) inhibitor. This suggests that plasma-induced $\gamma \mathrm{H} 2 \mathrm{AX}$ induction is a result of apoptosis induction rather than of plasma-derived ROS directly traveling through the cells and eventually to the nucleus to confer DNA damage. To confirm functionality of Z-VAD-FMK on inhibiting apoptosis, we measured caspase 3 and 7 activity (Figure 2(c)). Quantification at $4 \mathrm{~h}$ (Figure 2(d)) and $24 \mathrm{~h}$ (Figure $2(\mathrm{e})$ ) revealed a significant increase in nonapoptotic cells with all treatment modalities. The fact that UV-induced apoptosis but not $\mathrm{H} 2 \mathrm{AX}$ phosphorylation was abrogated with Z-VAD-FMK suggests that $\gamma \mathrm{H} 2 \mathrm{AX}$ induction was regulated by pathways not related to apoptosis, which was not the case for ROS conditions. Finally, using confocal laser scanning microscopy, we confirmed that $\gamma \mathrm{H} 2 \mathrm{AX}$ foci were majorly present in apoptotic cells showing fragmented nuclei (Figure 3(f)). Taken together, plasma and ROS but not UV-induced $\gamma \mathrm{H} 2 \mathrm{AX}$ was largely dependent on stress (p38-MAPK) and apoptosis (caspase) signaling pathways.

\subsection{Plasma-Mediated $\gamma H 2 A X$ Induction Does Not Correlate} to DNA DSB-Related Micronuclei. To confirm that plasma and ROS-induced $\gamma \mathrm{H} 2 \mathrm{AX}$ foci were a consequence of ROSinduced stress signaling and apoptosis-induced DNA DSBs rather than markers of direct ROS-induced DNA DSBs, we performed a functional assay on DNA DSBs, the cytokinesis-block micronucleus (MN) assay. Sufficient numbers of DNA DSBs lead to replication errors during DNA synthesis in G2 phase cells, which converts into micronuclei formation as genotoxic endpoint measurement [46]. The addition of cytochalasin B blocks cytoplasmic division due to inhibition of network formation of actin filaments. The result is an enrichment of binucleated (G2 phase) cells (BNCs) that can be quantitatively assessed with different DNA stains (Supplementary Figure 3a). Imaging (Supplementary Figure 3b) and quantification of BNCs (Supplementary Figure 3c) confirmed this principle, and we decided to use draq5 for subsequent experiments. Another observation was that the plasma and UV treatment time utilized in experiments were too toxic in combination with 

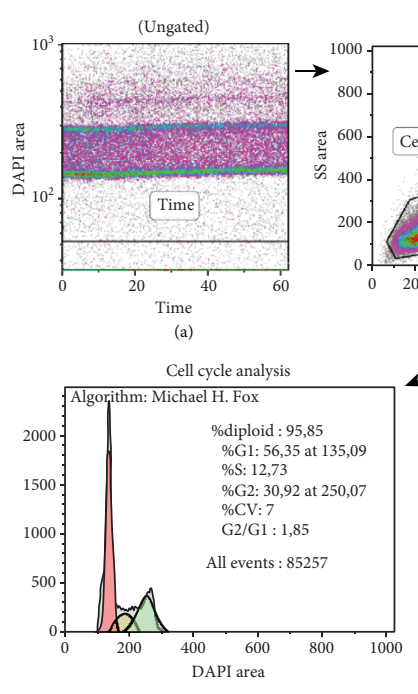

$\square \mathrm{G} 1$
$\square \mathrm{S}$
$\square \mathrm{G} 2$

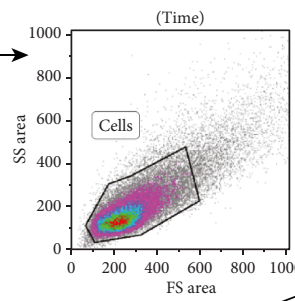

(b)<smiles>C1CCCC1</smiles>

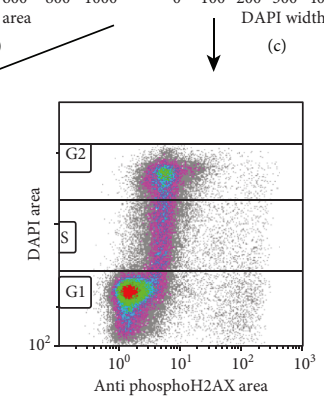

(e)

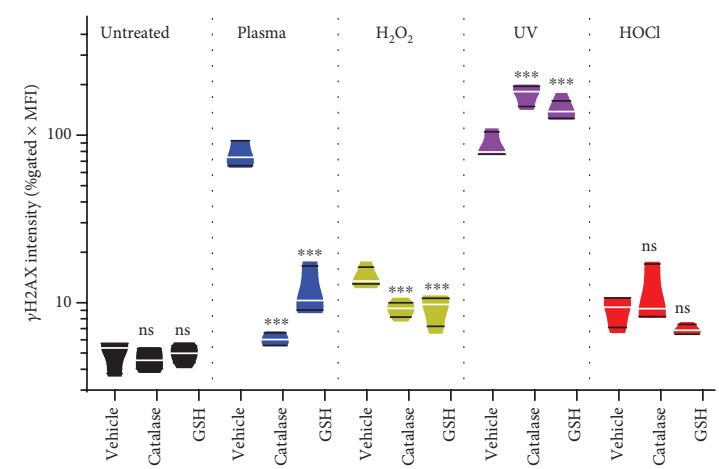

(f)
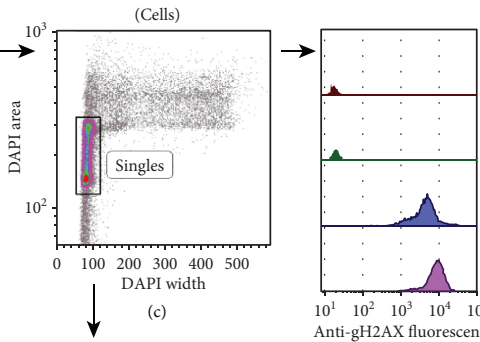

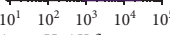
Anti-gH2AX fluorescence Unstained $\square$ Stained

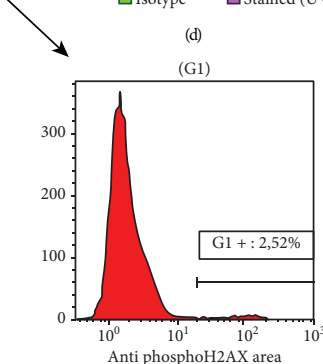

Anti phosphol 2 Ax
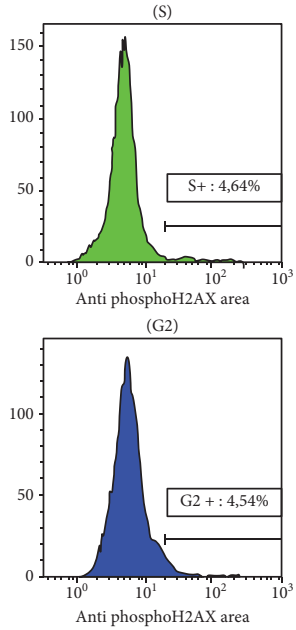
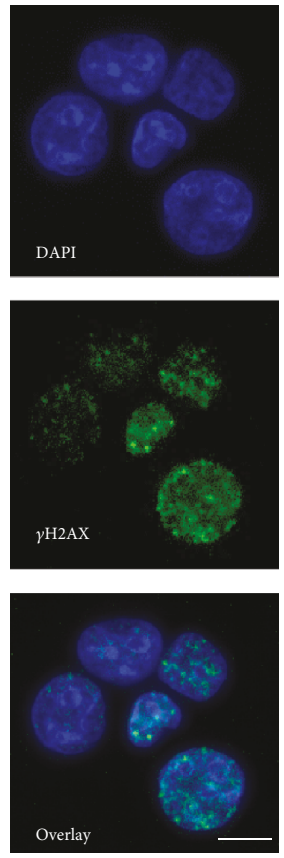

(h)

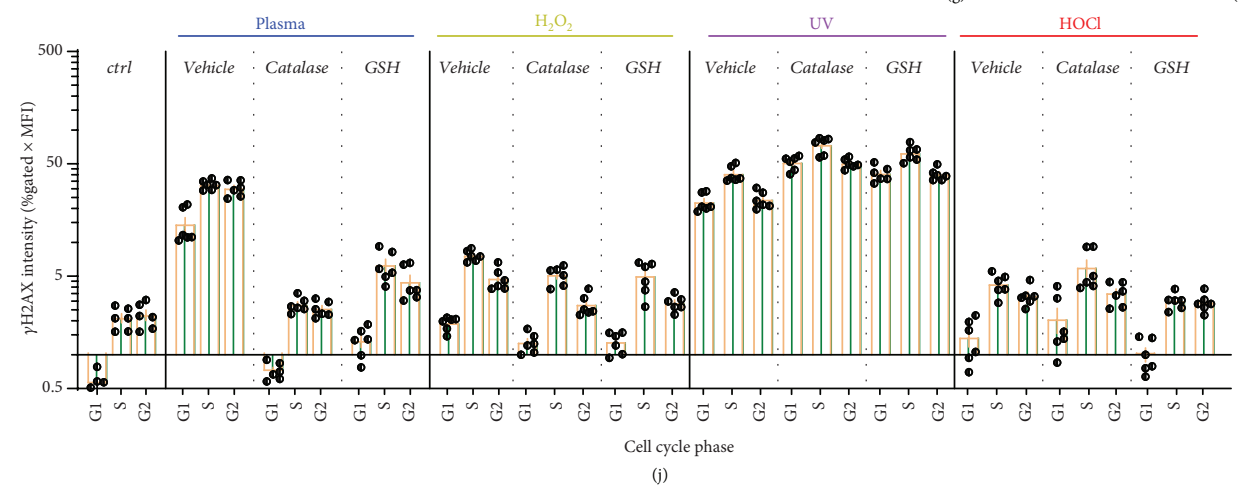

Figure 2: Analysis of $\gamma \mathrm{H} 2 \mathrm{AX}$ in TK6 cells and its relation to ROS. (a-c) Gating strategy of TK6 cells at $2 \mathrm{~h}$ after treatment with agents was done by first including cells in time (a) and forward (FS) and side scatter (SS) cell gate (b), before excluding doublets and subG1 cells for the singles gate (c). (d-e) Singles were then analyzed for total $\gamma \mathrm{H} 2 \mathrm{AX}$ as exemplified with representative fluorescence histogram overlay (d), subjected to algorithm-driven cell cycle analysis (e), or manually gated for each cell cycle phase (f) and subsequent determination of $\gamma \mathrm{H}_{2} \mathrm{AX}^{\text {hi }}$ cells in histograms (g). (h) Confirmation of $\gamma \mathrm{H} 2 \mathrm{AX}$ foci (green) in DAPI-stained nuclei (blue) by confocal laser scanning microscopy. (i) Quantification of total (independent of cell cycle phase) $\gamma \mathrm{H} 2 \mathrm{AX}$ with treatments and presence or absence of antioxidants. (j) Quantification of total $\gamma \mathrm{H} 2 \mathrm{AX}$ within each cell cycle phase at $2 \mathrm{~h}$ after treatment with agents in the presence or absence of antioxidants. Quantification ( $i, j$ ) was done by multiplying the percent of cells positive for $\gamma \mathrm{H} 2 \mathrm{AX}$ (\% gated) with the mean fluorescent intensity (MFI) of $\gamma \mathrm{H} 2 \mathrm{AX}^{+}$cells. Data show violin plots (i) or single values and mean \pm S.E. (j) of three independent experiments with duplicates each. Statistical analysis (i) within each treatment group was done with one-way ANOVA and Dunnett post hoc test to vehicle control. Scale bar $(\mathrm{h})$ is $10 \mu \mathrm{m}$; ns = not significant. 


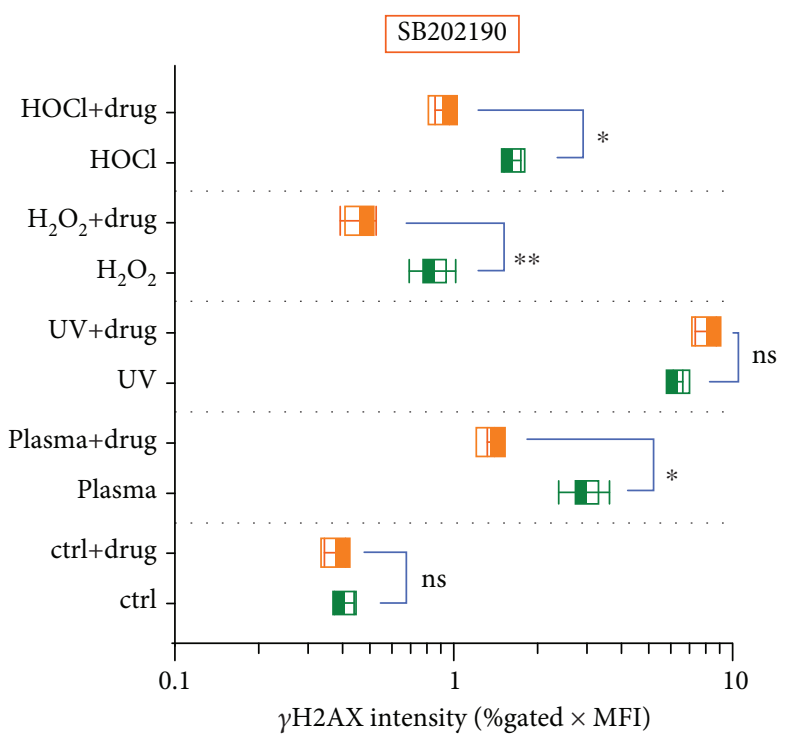

(a)

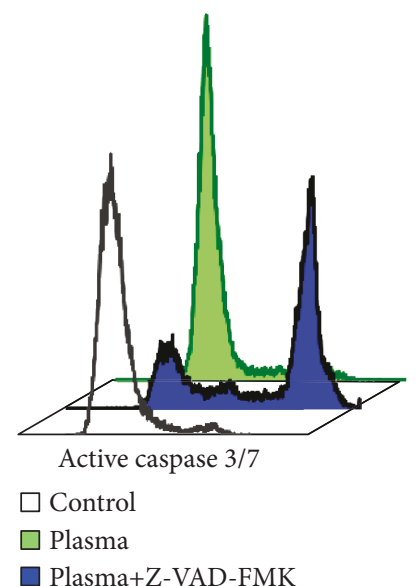

(c)

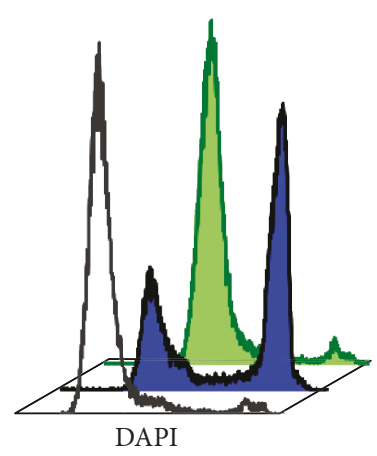

$24 \mathrm{~h}$

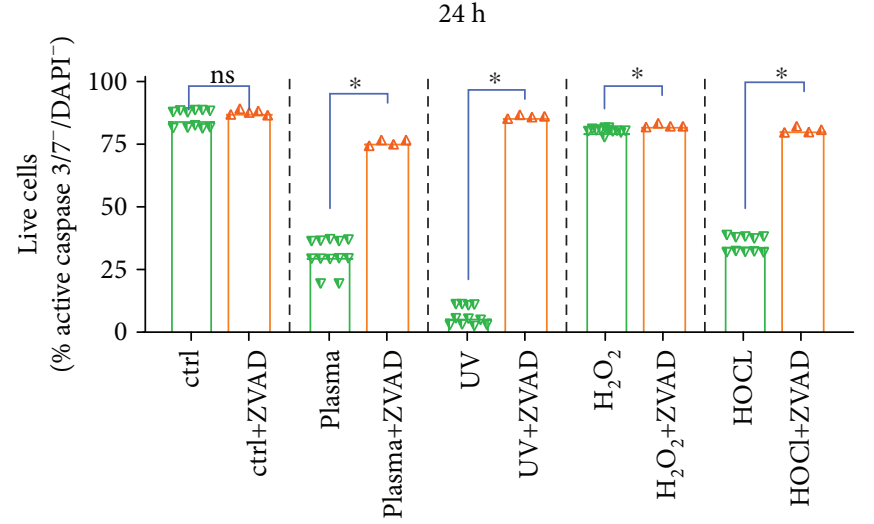

(e)

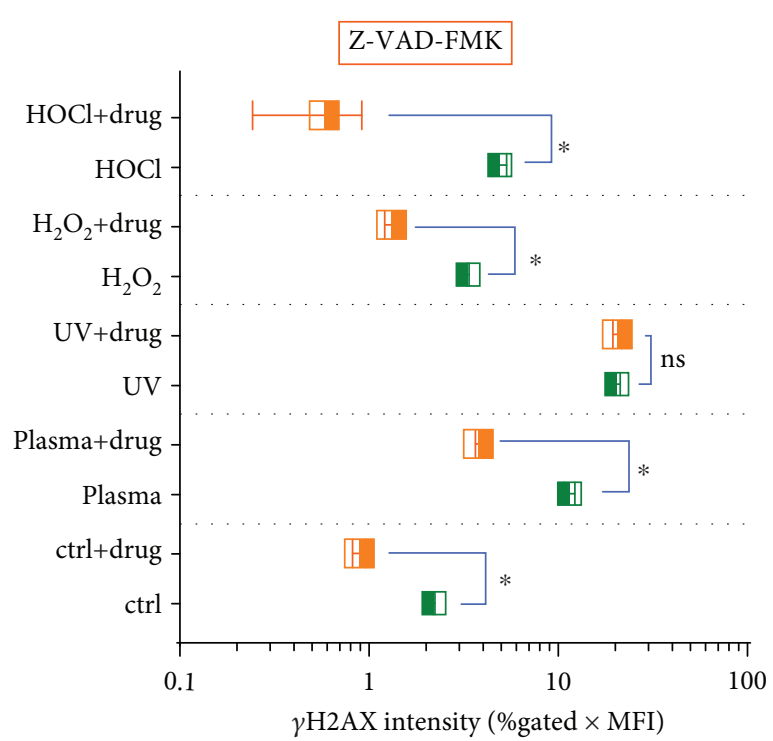

(b)

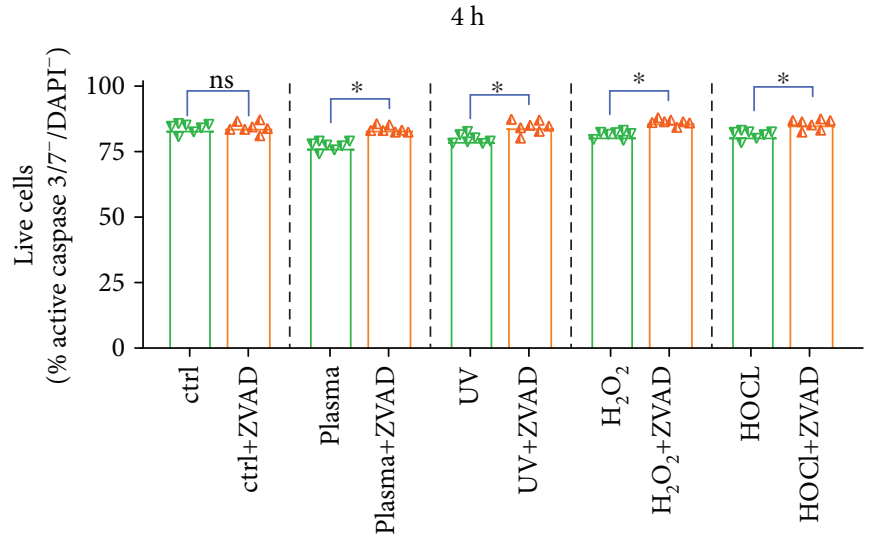

(d)
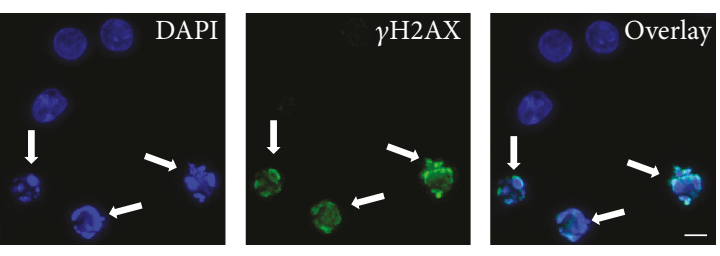

(f)

FIgURE 3: Dependence of ROS and UV-induced $\gamma \mathrm{H} 2 \mathrm{AX}$ expression on intracellular signaling and apoptosis. (a, b) $\gamma \mathrm{H} 2 \mathrm{AX}$ expression in cells preincubated with (a) SB202190 (p38 MAPK-inhibitor) or (b) Z-VAD-FMK (pan-caspase inhibitor) $2 \mathrm{~h}$ after exposure to various agents. (c) Representative overlay histograms of active caspase 3/7-stain (left) and terminally dead DAPI (right) in presence of absence of Z-VAD-FMK at $24 \mathrm{~h}$ after plasma treatment. (d-e) Quantification of apoptosis in presence or absence of Z-VAD-FMK at (d) $4 \mathrm{~h}$ and (e) $24 \mathrm{~h}$ after plasma treatment with $\gamma \mathrm{H} 2 \mathrm{AX}$-inducing agents. (f) Confocal laser scanning microscopy (DNA = DAPI, blue; $\gamma \mathrm{H} 2 \mathrm{AX}=$ green) of TK6 cells with arrows pointing at apoptotic (cells with fragmented nuclei) cells being positive for $\gamma \mathrm{H} 2 \mathrm{AX}$. Data show box plots (a,b) and single data and mean (d, e) of two to four independent experiments with several replicates each. Statistical analysis was done using $t$-test. Scale bar (f) is $10 \mu \mathrm{m} ; \mathrm{n} . \mathrm{s} .=$ not significant. 
cytochalasin B, leaving only few cells to analyze at $48 \mathrm{~h}$ posttreatment. Therefore, plasma and UV treatment time was reduced to $2.5 \mathrm{~s}$ and $24 \mathrm{~s}$, respectively, which still generated significantly more $\gamma \mathrm{H} 2 \mathrm{AX}$ signal compared to untreated control (Figures 4(a) and 4(b)). By applying customized mathematical operands, several masks were develop to clearly identify and quantify BNCs as well as $\mathrm{MN}$ within the population of BNCs in an algorithm-based, unbiased fashion (Figure 4(c)) across millions of cells. Final analysis showed a significant increase in $\mathrm{MN}$ formation with UV but not plasma treatment. A chemical genotoxic agent (MMS) was installed as additional control in this experiment, which differed significantly from untreated cells (Figure 4(d)). As additional quality control, the average number of cells analyzed in these experiments was quantified and was similar among all conditions (Supplementary Figure 3d). In sum, MN formation correlated with $\gamma \mathrm{H} 2 \mathrm{AX}$ induction for UV treatment, which directly acts on cellular DNA, but not for plasma treatment, which acts on cells by generating exogenous ROS that subsequently diffuse to cells to exert their stress and apoptosis-inducing but not directly DNA-damaging function.

\section{Discussion}

DNA damage and the DNA damage response are important elements in medical treatment modalities, such as radiation therapy and chemotherapeutic drugs in several medical fields including in oncology [3]. For example, the anticancer drug doxorubicin can both induce DNA DSBs and generate ROS, leading to $\gamma \mathrm{H} 2 \mathrm{AX}$ induction [47-49]. Cell metabolism, oxidative stress, and DNA damage are often intertwined and difficult to study independently, leading to the general assumption of $\gamma \mathrm{H} 2 \mathrm{AX}$ foci being a hallmark of DNA DSBs and damage. We here provide evidence that exogenous ROS added experimentally or generated with cold physical plasmas led to $\gamma \mathrm{H} 2 \mathrm{AX}$ induction only in case of apoptosis, and without long-term genotoxic effects. In such setting, the presence of $\gamma \mathrm{H} 2 \mathrm{AX}$ may be a consequence of low oxidative stress rather than an indicator of DNA damage. Recent data suggest $\gamma \mathrm{H} 2 \mathrm{AX}$ to even play in pivotal role in antioxidant defense signaling [50]. H2AX-knockout cells showed increase endogenous ROS levels and failed to activate the antioxidant response elements through nuclear factor E2-related factor 2, Nrf2 [51], along with mitochondrial damage [29].

In our study, we used UV-B radiation as positive control for $\gamma \mathrm{H} 2 \mathrm{AX}$ and micronuclei induction. In contrast to exogenous ROS (plasma, $\mathrm{H}_{2} \mathrm{O}_{2}$, or $\mathrm{HOCl}$ ), occurrence of $\gamma \mathrm{H} 2 \mathrm{AX}$ was independent of the use of antioxidants and maximum in S-phase cells. The latter corroborates previous findings, where also a repression of $\gamma \mathrm{H} 2 \mathrm{AX}$ induction with PI3K inhibition using $5 \mathrm{mM}$ of caffeine was found [52]. We did not find such decrease with PI3K inhibitors wortmannin and Ly294002, which may be due to different cell types and concentrations tested. Another study found ATR kinase to be the crucial determinant for UV-induced H2AX phosphorylation and confirmed our findings of maximum $\gamma \mathrm{H} 2 \mathrm{AX}$ induction at $2 \mathrm{~h}$ after treatment prior to onset of intermediate stages of apoptosis where $\gamma \mathrm{H} 2 \mathrm{AX}$ dramatically increases [53]. The ability of UV-B enhancing the frequency of $\mathrm{MN}$ in cells has been reported before $[54,55]$. Interestingly, catalase decreased oxidation in UV-treated cells but not H2AX phosphorylation. UV generates ROS in the intracellular as well as extracellular compartment [56]. As the experimentally added catalase only acts in the extracellular compartment, a partial protection from oxidation was observed without protecting the DNA (intracellular compartment) from UV-mediated ROS and damage.

With exogenous ROS (plasma, $\mathrm{H}_{2} \mathrm{O}_{2}, \mathrm{HOCl}$ ), we observed a strong dependence on p38-MAPK signaling and caspase activation in TK6 cells. This is in line with previous findings using oxaliplatin, an antitumor tumor drug leading to DNA DSBs, where pretreatment of cells with SB202190 (p38-MAPK inhibitor) and Z-VAD-FMK (caspase inhibitor) abrogated oxaliplatin-induced $\gamma \mathrm{H} 2 \mathrm{AX}$ induction and apoptosis in HCT116 cells [57]. In leukemia cells, it was reported that $\gamma \mathrm{H} 2 \mathrm{AX}$ (or blockage of H2AX phosphorylation by SB202190) expression sensitizes cells to apoptosis, suggesting a pivotal role of $\gamma \mathrm{H} 2 \mathrm{AX}$ in cell death signaling [58]. This is supported by findings with $\mathrm{H} 2 \mathrm{AX}$-knockout fibroblasts, which upon UV treatment activates caspase 3 but cannot activate caspase-activated DNAse (CAD), a crucial step in DNA fragmentation required for apoptosis [59]. Another form of regulated cell death (RCD) leading to widespread DNA fragmentation is parthanatos, but this mode of RCD is independent of apoptotic caspases [60]. Hence, parthanatos is not a main mechanism in our study because we observed apoptosis-induced and caspase-dependent DNA fragmentation. Hence, $\gamma \mathrm{H} 2 \mathrm{AX}$ is heavily intertwined in cell death signaling and our study supports this notion as caspase inhibition abrogated both H2AX phosphorylation and apoptosis.

Heavy $\mathrm{H} 2 \mathrm{AX}$ phosphorylation indicates toxic numbers of DNA DSBs in, e.g., ionizing radiation, UV treatment, replication, and apoptosis. Contrasting radiation-induced DNA DSBs, we found $\gamma \mathrm{H} 2 \mathrm{AX}$ to be a consequence of ROS-induced apoptosis rather than its cause. T lymphocytes are very sensitive towards (plasma-induced) oxidative stress [61-64]. This is due to (low-dose) ROS acting as proapoptotic and redox-signaling agents and not as toxic molecules per se [65]. In our study, e.g., few micromolar $\mathrm{H}_{2} \mathrm{O}_{2}$ on 250,000 cells were sufficient to induce cell death. The concentrations of, e.g., $\mathrm{H}_{2} \mathrm{O}_{2}$ used in many genotoxicity studies are 10-50-fold higher at lower absolute cell numbers [66-68]. So far, only few studies in plasma medicine investigated genotoxicity in cells and tissues using non- $\gamma \mathrm{H} 2 \mathrm{AX}$ assays, and the once that have did not report mutagenic effects of plasma treatment. Using the hypoxanthine-guanine phosphoribosyl-transferase (HPRT) assay and the MN assay in V79 cells, plasma treatment failed to induce mutagenic effects when exposing cells to the plasma of the kINPen or its products [69], or when using another plasma source designed for medical application at microbicidal concentrations [70, 71]. Modulation of the feed gas composition of the kINPen yielded similar results [43]. Micronuclei have also been quantified in vivo 

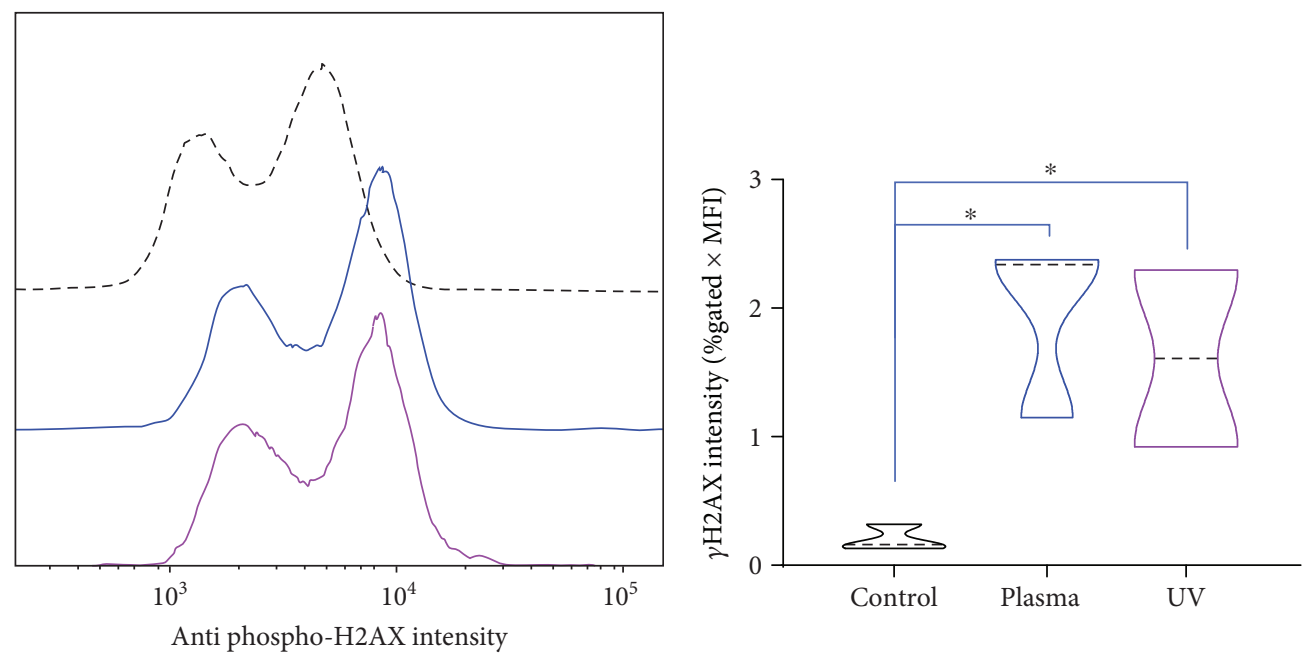

\section{$\square$ Control \\ $\square$ Plasma \\ $\square$ UV}

(a)

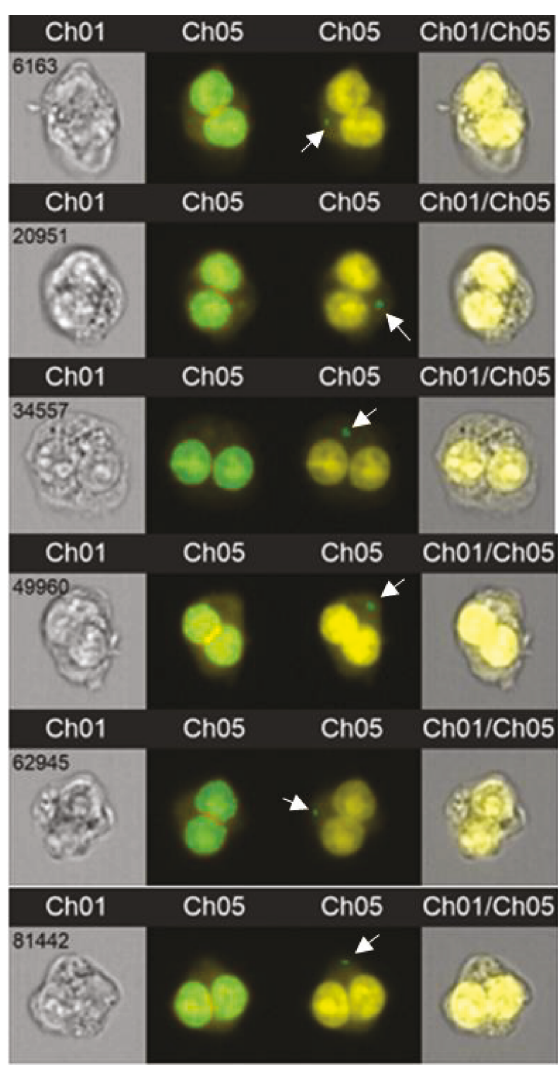

(c)

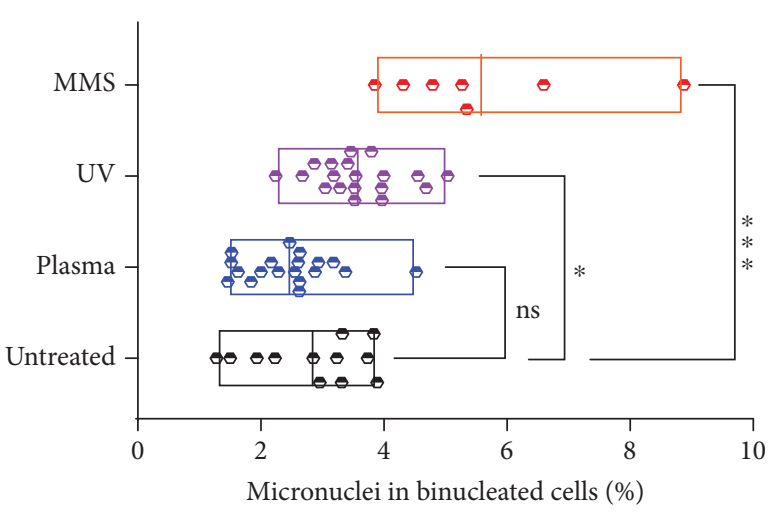

(d)

FIGURE 4: Correlation of $\gamma \mathrm{H} 2 \mathrm{AX}$ expression and micronuclei formation. (a, b) Representative histogram overlay $\gamma \mathrm{H} 2 \mathrm{AX}$ fluorescence (a) and its quantification (b) in control as well as plasma and UV-treated cells. (c) Representative images (left: brightfield, right: overlay) of highthroughput imaging cytometry of TK6 cells to analyze draq5-stained nuclei (yellow) with masks for binucleated cells (middle left large green overlays) and micronuclei (middle right small green overlays with white arrows). (d) Quantification of micronuclei in binucleated TK6 cells that were left untreated or exposed to plasma, UV light, or methyl methanesulfonate (MMS). Data are from two (b) and three to four (d) independent experiments with several replicates each. Data show violin plots (b) and min-to-max floating bars (d). Statistical analysis was done with one-way ANOVA. 
in the hen's egg model after treatment with cyclophosphamide or methotrexate (as positive control), or cold physical plasma generated with the kINPen. Results showed the absence of genotoxicity-indicating MN with plasma treatment compared to positive controls [72]. In human tissue exposed to cold physical plasma at short, intermediate, and long treatment times, an increase of $\gamma \mathrm{H} 2 \mathrm{AX}$ was not observed when compared to untreated control tissue [73]. Moreover, in a one-year follow-up of mice (human equivalent of 65 years) treated six times with plasma within 2 weeks, no occurrence of malignant lesions was observed anywhere in the body as shown by immunohistochemistry and PETCT and MRI scan [74].

ROS can also induce lipid peroxidation [75], which can contribute to DNA damage. However, for $\mathrm{H}_{2} \mathrm{O}_{2}$-which gave large $\gamma \mathrm{H} 2 \mathrm{AX}$ signals-concentration reported for lipid peroxidation exceeds the one used in our study by 50 -fold [76]. For lipid vesicles, $\mathrm{H}_{2} \mathrm{O}_{2}$ is ineffective in the absence of the Fenton reaction [77], even at concentration 5000 times of that used in our work [78]. For $\mathrm{H}_{2} \mathrm{O}_{2}$ treatment in our study, caspase inhibition decreased $\mathrm{H}_{2} \mathrm{O}_{2}$-incuded $\gamma \mathrm{H} 2 \mathrm{AX}$ to background levels, which argues against $\mathrm{H}_{2} \mathrm{O}_{2}$ induced lipid peroxidation as major mechanism for DNA DSBs. Moreover, if lipid peroxidation would have contributed to plasma-induced DNA damage, e.g., via UVmediated photolysis and hydroxyl radical generation, addition of catalase would not have abrogated the increase observed in $\gamma \mathrm{H} 2 \mathrm{AX}$.

Our results are of relevance for medical plasmas, while findings may be different for industrial plasma applications. Atmospheric and room temperature plasma (ARTP) has been recently described as tool for mutation breeding in microorganisms [79-81]. Its efficacy seemed greater than that of several conventional methods, e.g., chemicals and UV radiation [82], and ARTP can also be combined with such methods [83]. As result, ARTP was found to increase production of, for instance, $\alpha$-ketoglutaric acid [84], biofuel [85], polysaccharides [86, 87], arachidonic acid [88], erythritol [89], l-arginine [90], alkaline $\alpha$-amylase [91, 92], d-lactic acid [93], lycopene [94], and carotenoids and lipids [95] in different types of microorganisms. However, it is important to mention that these plasma sources are not intended for medical applications. Hence, they may differ substantially in their geometry and power consumption, leading to enhanced UV radiation, ROS generation, and electrical discharges. In our study, we used a low-energy [96] and clinically effective $[8,97,98]$ plasma jet complying to European regulations (e.g., generation of ozone, UV, and leak currents), which is not true for the majority of other plasma devices reported in experimental studies.

A limitation of our study is the lack of short-term kinetic measurements of $\gamma \mathrm{H} 2 \mathrm{AX}$ and (onset of) apoptosis. Moreover, $\gamma \mathrm{H} 2 \mathrm{AX}$ foci expand over time [99], making it difficult to distinguish between many foci with low intensity vs. few foci with high intensity (and anything in between) in our flow cytometry data. Additionally, other proteins including Nbs1, 53BP1, and Brcal are recruited to and hence mark DNA DSBs [31], which may be investigated in future studies.

\section{Conclusion}

Cold physical plasma-induced $\gamma \mathrm{H} 2 \mathrm{AX}$ marks DNA DSBs as a consequence of oxidative stress and apoptosis in vitro. Upon blocking apoptosis and p38 MAPK signaling, increased $\gamma \mathrm{H} 2 \mathrm{AX}$ with plasma treatment was abolished, arguing that $\mathrm{H} 2 \mathrm{AX}$ phosphorylation is a secondary event in redox or apoptotic signaling rather than a primary consequence of direct ROS-mediated DNA damage. In contrast to UV treatment, exposure to plasma did not correlate with long-lasting genotoxic effects as indicated using the micronucleus assay. Hence, $\gamma \mathrm{H} 2 \mathrm{AX}$ measurements in plasma medical research should be interpreted with care, keeping in mind the pleiotropic roles of this molecule in redox sensing and apoptotic pathways.

\section{Data Availability}

The data used to support the findings of this study are available from the corresponding author upon request.

\section{Conflicts of Interest}

The authors declare that there is no conflict of interest regarding the publication of this paper.

\section{Acknowledgments}

This work was funded by the German Federal Ministry of Education and Research (BMBF), grant numbers 03Z22DN11 and 03Z22DN12. C.S.S. received funding from the Gerhard-Domagk Foundation.

\section{Supplementary Materials}

Supplementary Figure S1: (a) metabolic activity in TK6 cells at $24 \mathrm{~h}, 48 \mathrm{~h}$, and $72 \mathrm{~h}$ after exposure to $\gamma \mathrm{H} 2 \mathrm{AX}$-inducing agents; (b) quantification of nonterminally dead (DAPI-) TK6 cells at $6 \mathrm{~h}$ after exposure to different concentrations or treatment times of $\gamma \mathrm{H} 2 \mathrm{AX}$-inducing agents; (c) dilution series of anti- $\gamma \mathrm{H} 2 \mathrm{AX}$ antibody in control and UV-treated TK6 cells to obtain optimal antibody concentration; (d) kinetic experiment of $\gamma \mathrm{H} 2 \mathrm{AX}$ intensity in control or plasma and UV-treated TK6 cells; (e) $\gamma \mathrm{H} 2 \mathrm{AX}$ intensity in each cell cycle phase of untreated cells incubated with vehicle, catalase, and GSH; (f) incubation with antioxidant NAC increased $\gamma \mathrm{H} 2 \mathrm{AX}$ intensity with all treatments as well as in untreated cells and therefore was not used in this study. Supplementary Figure S2: serial dilutions of inhibitors. (a) SB202190 (p38MAPK inhibitor) was used in the study (Figure 3(a)); (b) SP600125 (JNK inhibitor) disqualified due to the increase of $\gamma \mathrm{H} 2 \mathrm{AX}$ in untreated cells upon incubation with the drug; (c) Ly294002 (PI3K inhibitor) did not decrease $\gamma \mathrm{H} 2 \mathrm{AX}$ in plasma-treated cells; (d) wortmannin (PI3K inhibitor) disqualified due to the increase of $\gamma \mathrm{H} 2 \mathrm{AX}$ in untreated cells upon incubation with the drug; (e) Z-VAD-FMK (pan-caspase inhibitor) was used in the study (Figure 3(b)); (f) KU55933 (ATM-kinase inhibitor) showed a small decrease in $\gamma \mathrm{H} 2 \mathrm{AX}$, which (g) was not significant with any treatment in three independent repeats. Supplementary Figure S3: 
optimization of the micronucleus assay. (a) cell cycle analysis of untreated and treated (cytochalasin B for $24 \mathrm{~h}$ ) TK6 cells with different DNA-binding dyes; (b) representative images of cells in brightfield (Ch05 or Ch01) and DNA-binding dye (Ch1 or Ch5) showing binucleated cells (BNCs); (c) quantification of binucleated cells stained with four different DNA-binding dyes via a complex software algorithm designed to create a specific set of masks to BNCs as described before [1], we aimed at a low amount of BNCs to obtain a high specificity for micronuclei leading to the choice of draq 5 for main experiments; (d) mean total count of cells in samples from each condition. (Supplementary Materials)

\section{References}

[1] S. H. Macphail, J. P. BanÁth, T. Y. Yu, E. H. M. Chu, H. Lambur, and P. L. Olive, "Expression of phosphorylated histone H2AX in cultured cell lines following exposure to X-rays," International Journal of Radiation Biology, vol. 79, no. 5, article 12943243, pp. 351-359, 2003.

[2] E. P. Rogakou, D. R. Pilch, A. H. Orr, V. S. Ivanova, and W. M. Bonner, "DNA double-stranded breaks induce histone H2AX phosphorylation on serine 139," Journal of Biological Chemistry, vol. 273, no. 10, pp. 5858-5868, 1998.

[3] L.-J. Mah, A. El-Osta, and T. C. Karagiannis, " $\gamma \mathrm{H} 2 \mathrm{AX}$ : a sensitive molecular marker of DNA damage and repair," Leukemia, vol. 24, no. 4, pp. 679-686, 2010.

[4] D. Yan, J. H. Sherman, and M. Keidar, "Cold atmospheric plasma, a novel promising anti-cancer treatment modality," Oncotarget, vol. 8, no. 9, pp. 15977-15995, 2017.

[5] S. Bekeschus, K. Rodder, B. Fregin et al., "Toxicity and immunogenicity in murine melanoma following exposure to physical plasma-derived oxidants," Oxidative Medicine and Cellular Longevity, vol. 2017, Article ID 4396467, 12 pages, 2017.

[6] A. Lin, Y. Gorbanev, J. de Backer et al., "Non-thermal plasma as a unique delivery system of short-lived reactive oxygen and nitrogen species for immunogenic cell death in melanoma cells," Advanced Science, vol. 6, no. 6, p. 1802062, 2019.

[7] G. Pasqual-Melo, R. K. Gandhirajan, I. Stoffels, and S. Bekeschus, "Targeting malignant melanoma with physical plasmas," Clinical Plasma Medicine, vol. 10, pp. 1-8, 2018.

[8] H.-R. Metelmann, C. Seebauer, V. Miller et al., "Clinical experience with cold plasma in the treatment of locally advanced head and neck cancer," Clinical Plasma Medicine, vol. 9, pp. 6-13, 2018.

[9] S. Reuter, T. von Woedtke, and K. D. Weltmann, "The kINPen-a review on physics and chemistry of the atmospheric pressure plasma jet and its applications," Journal of Physics D: Applied Physics, vol. 51, no. 23, p. 233001, 2018.

[10] S. Bekeschus, J. Kolata, C. Winterbourn et al., "Hydrogen peroxide: a central player in physical plasma-induced oxidative stress in human blood cells," Free Radical Research, vol. 48, no. 5, pp. 542-549, 2014.

[11] K. P. Arjunan, G. Friedman, A. Fridman, and A. M. Clyne, "Non-thermal dielectric barrier discharge plasma induces angiogenesis through reactive oxygen species," Journal of The Royal Society Interface, vol. 9, no. 66, pp. 147-157, 2012.

[12] D. B. Graves, "The emerging role of reactive oxygen and nitrogen species in redox biology and some implications for plasma applications to medicine and biology," Journal of Physics D: Applied Physics, vol. 45, no. 26, p. 263001, 2012.

[13] S. Arndt, E. Wacker, Y. F. Li et al., "Cold atmospheric plasma, a new strategy to induce senescence in melanoma cells," Experimental Dermatology, vol. 22, no. 4, pp. 284-289, 2013.

[14] J. W. Chang, S. U. Kang, Y. S. Shin et al., "Non-thermal atmospheric pressure plasma induces apoptosis in oral cavity squamous cell carcinoma: Involvement of DNA-damagetriggering sub-G1 arrest via the ATM/p53 pathway," Arch Biochem Biophys, vol. 545, pp. 133-140, 2014.

[15] F. Judée, C. Fongia, B. Ducommun, M. Yousfi, V. Lobjois, and N. Merbahi, "Short and long time effects of low temperature plasma activated media on 3D multicellular tumor spheroids," Scientific Reports, vol. 6, no. 1, 2016.

[16] N. Kaushik, N. Uddin, G. B. Sim et al., "Responses of solid tumor cells in DMEM to reactive oxygen species generated by non-thermal plasma and chemically induced ROS systems," Scientific Reports, vol. 5, no. 1, 2015.

[17] J. M. Plewa, M. Yousfi, C. Frongia et al., "Low-temperature plasma-induced antiproliferative effects on multi-cellular tumor spheroids," New Journal of Physics, vol. 16, no. 4, 2014.

[18] S. K. Sagwal, G. Pasqual-Melo, Y. Bodnar, R. K. Gandhirajan, and S. Bekeschus, "Combination of chemotherapy and physical plasma elicits melanoma cell death via upregulation of SLC22A16," Cell Death \& Disease, vol. 9, no. 12, 2018.

[19] R. Sensenig, S. Kalghatgi, E. Cerchar et al., "Non-thermal plasma induces apoptosis in melanoma cells via production of intracellular reactive oxygen species," Annals of Biomedical Engineering, vol. 39, no. 2, pp. 674-687, 2011.

[20] H. Jablonowski, J. Santos Sousa, K. D. Weltmann, K. Wende, and S. Reuter, "Quantification of the ozone and singlet delta oxygen produced in gas and liquid phases by a non-thermal atmospheric plasma with relevance for medical treatment," Scientific Reports, vol. 8, no. 1, p. 12195, 2018.

[21] H. Jablonowski, A. Schmidt-Bleker, K. D. Weltmann, T. von Woedtke, and K. Wende, "Non-touching plasma-liquid interaction - where is aqueous nitric oxide generated?," Physical Chemistry Chemical Physics, vol. 20, no. 39, pp. 2538725398, 2018.

[22] H. Jablonowski and T. von Woedtke, "Research on plasma medicine-relevant plasma-liquid interaction: what happened in the past five years?" Clinical Plasma Medicine, vol. 3, no. 2, pp. 42-52, 2015.

[23] M. B. Hampton and K. M. O'Connor, "Peroxiredoxins and the regulation of cell death," Molecules and Cells, vol. 39, no. 1, pp. 72-76, 2016.

[24] C. Gu, J. Luo, X. Lu et al., "REV7 confers radioresistance of esophagus squamous cell carcinoma by recruiting PRDX2," Cancer Science, vol. 110, no. 3, pp. 962-972, 2019.

[25] W. M. Bonner, C. E. Redon, J. S. Dickey et al., " $\gamma \mathrm{H} 2 \mathrm{AX}$ and cancer," Nature Reviews Cancer, vol. 8, no. 12, pp. 957-967, 2008.

[26] O. A. Sedelnikova, C. E. Redon, J. S. Dickey, A. J. Nakamura, A. G. Georgakilas, and W. M. Bonner, "Role of oxidatively induced DNA lesions in human pathogenesis," Mutation Research/Reviews in Mutation Research, vol. 704, no. 1-3, pp. 152-159, 2010.

[27] P. Rybak, A. Hoang, L. Bujnowicz et al., "Low level phosphorylation of histone $\mathrm{H} 2 \mathrm{AX}$ on serine $139(\gamma \mathrm{H} 2 \mathrm{AX})$ is not associated with DNA double-strand breaks," Oncotarget, vol. 7, no. 31, pp. 49574-49587, 2016. 
[28] Y. Ichijima, R. Sakasai, N. Okita, K. Asahina, S. Mizutani, and $\mathrm{H}$. Teraoka, "Phosphorylation of histone H2AX at M phase in human cells without DNA damage response," Biochemical and Biophysical Research Communications, vol. 336, no. 3, pp. 807-812, 2005.

[29] J. H. Jeong, Y. Cheol Kang, Y. Piao, S. Kang, and Y. K. Pak, "miR-24-mediated knockdown of H2AX damages mitochondria and the insulin signaling pathway," Experimental \& Molecular Medicine, vol. 49, no. 4, p. e313, 2017.

[30] T. Tanaka, X. Huang, H. D. Halicka et al., "Cytometry of ATM activation and histone $\mathrm{H} 2 \mathrm{AX}$ phosphorylation to estimate extent of DNA damage induced by exogenous agents," Cytometry Part A, vol. 71A, no. 9, pp. 648-661, 2007.

[31] A. Celeste, O. Fernandez-Capetillo, M. J. Kruhlak et al., "Histone $\mathrm{H} 2 \mathrm{AX}$ phosphorylation is dispensable for the initial recognition of DNA breaks," Nature Cell Biology, vol. 5, no. 7, pp. 675-679, 2003.

[32] M. A. Kang, E. Y. So, A. L. Simons, D. R. Spitz, and T. Ouchi, "DNA damage induces reactive oxygen species generation through the H2AX-Nox1/Rac1 pathway," Cell Death \& Disease, vol. 3, no. 1, p. e249, 2012.

[33] S. Burma, B. P. Chen, M. Murphy, A. Kurimasa, and D. J. Chen, "ATM phosphorylates histone $\mathrm{H} 2 \mathrm{AX}$ in response to DNA double-strand breaks," Journal of Biological Chemistry, vol. 276, no. 45, pp. 42462-42467, 2001.

[34] B. Mukherjee, C. Kessinger, J. Kobayashi et al., "DNA-PK phosphorylates histone H2AX during apoptotic DNA fragmentation in mammalian cells," DNA Repair, vol. 5, no. 5, pp. 575-590, 2006.

[35] Z. Guo, R. Deshpande, and T. T. Paull, "ATM activation in the presence of oxidative stress," Cell Cycle, vol. 9, no. 24, pp. 4805-4811, 2010.

[36] A. Sharma, K. Singh, and A. Almasan, "Histone H2AX phosphorylation: a marker for DNA damage," Methods in Molecular Biology, vol. 920, pp. 613-626, 2012.

[37] M. Lukamowicz, M. Kirsch-Volders, W. Suter, and A. Elhajouji, "In vitro primary human lymphocyte flow cytometry based micronucleus assay: simultaneous assessment of cell proliferation, apoptosis and MN frequency," Mutagenesis, vol. 26, no. 6, pp. 763-770, 2011.

[38] M. Lukamowicz, K. Woodward, M. Kirsch-Volders, W. Suter, and A. Elhajouji, "A flow cytometry based in vitro micronucleus assay in TK6 cells-Validation using early stage pharmaceutical development compounds," Environmental and Molecular Mutagenesis, vol. 52, no. 5, pp. 363-372, 2011.

[39] S. Bekeschus, A. Schmidt, K.-D. Weltmann, and T. von Woedtke, "The plasma jet kINPen - a powerful tool for wound healing," Clinical Plasma Medicine, vol. 4, no. 1, pp. 19-28, 2016.

[40] S. Bekeschus, A. Schmidt, F. Niessner, T. Gerling, K. D. Weltmann, and K. Wende, "Basic research in plasma medicine - a throughput approach from liquids to cells," Journal of Visualized Experiments, no. 129, 2017.

[41] A. Budiyanto, N. U. Ahmed, A. Wu et al., "Protective effect of topically applied olive oil against photocarcinogenesis following UVB exposure of mice," Carcinogenesis, vol. 21, no. 11, pp. 2085-2090, 2000.

[42] M. Kirsch-Volders, G. Plas, A. Elhajouji et al., "The in vitro MN assay in 2011: origin and fate, biological significance, protocols, high throughput methodologies and toxicological rele- vance," Archives of Toxicology, vol. 85, no. 8, pp. 873-899, 2011.

[43] S. Bekeschus, A. Schmidt, A. Kramer et al., "High throughput image cytometry micronucleus assay to investigate the presence or absence of mutagenic effects of cold physical plasma," Environmental and Molecular Mutagenesis, vol. 59, no. 4, pp. 268-277, 2018.

[44] S. Bekeschus, T. von Woedtke, A. Kramer, K.-D. Weltmann, and K. Masur, "Cold physical plasma treatment alters redox balance in human immune cells," Plasma Medicine, vol. 3, no. 4, pp. 267-278, 2013.

[45] M. Lobrich, A. Shibata, A. Beucher et al., " $\gamma \mathrm{H} 2 \mathrm{AX}$ foci analysis for monitoring DNA double-strand break repair: Strengths, limitations and optimization," Cell Cycle, vol. 9, no. 4, pp. 662-669, 2010.

[46] G. P. Watters, D. J. Smart, J. S. Harvey, and C. A. Austin, "H2AX phosphorylation as a genotoxicity endpoint," Mutation Research/Genetic Toxicology and Environmental Mutagenesis, vol. 679, no. 1-2, pp. 50-58, 2009.

[47] E. U. Kurz, P. Douglas, and S. P. Lees-Miller, "Doxorubicin activates ATM-dependent phosphorylation of multiple downstream targets in part through the generation of reactive oxygen species," Journal of Biological Chemistry, vol. 279, no. 51, pp. 53272-53281, 2004.

[48] S. Zhang, X. Liu, T. Bawa-Khalfe et al., "Identification of the molecular basis of doxorubicin-induced cardiotoxicity," Nature Medicine, vol. 18, no. 11, pp. 1639-1642, 2012.

[49] P. K. Singal and N. Iliskovic, "Doxorubicin-induced cardiomyopathy," New England Journal of Medicine, vol. 339, no. 13, pp. 900-905, 1998.

[50] A. Schmidt, S. Bekeschus, K. Jarick, S. Hasse, T. von Woedtke, and K. Wende, "Cold physical plasma modulates p53 and mitogen-activated protein kinase signaling in keratinocytes," Oxidative Medicine and Cellular Longevity, vol. 2019, Article ID 7017363, 16 pages, 2019.

[51] U. Weyemi, B. D. Paul, A. M. Snowman et al., "Histone H2AX deficiency causes neurobehavioral deficits and impaired redox homeostasis," Nature Communications, vol. 9, no. 1, 2018.

[52] H. D. Halicka, X. Huang, F. Traganos, M. A. King, W. Dai, and Z. Darzynkiewicz, "Histone H2AX phosphorylation after cell irradiation with UV-B: relationship to cell cycle phase and induction of apoptosis," Cell Cycle, vol. 4, no. 2, pp. 338-344, 2004.

[53] S. Hanasoge and M. Ljungman, " $\mathrm{H} 2 \mathrm{AX}$ phosphorylation after UV irradiation is triggered by DNA repair intermediates and is mediated by the ATR kinase," Carcinogenesis, vol. 28, no. 11, pp. 2298-2304, 2007.

[54] D. Bettega, P. Calzolari, L. Doneda, F. Belloni, L. Tallone, and J. L. Redpath, "Differential effectiveness of solar UVB subcomponents in causing cell death, oncogenic transformation and micronucleus induction in human hybrid cells," International Journal of Radiation Biology, vol. 79, no. 3, pp. 211-216, 2003.

[55] A. Ferahbas, H. Donmez-Altuntas, Z. Hamurcu, E. Aktas, and S. Utas, "Micronucleus evaluation in mitogen-stimulated lymphocytes of narrow-band (311 nm TL01) UVB-treated patients," Photodermatology, Photoimmunology and Photomedicine, vol. 20, no. 2, pp. 81-85, 2004.

[56] T. Herrling, K. Jung, and J. Fuchs, "Measurements of UVgenerated free radicals/reactive oxygen species (ROS) in skin," Spectrochimica Acta Part A: Molecular and Biomolecular Spectroscopy, vol. 63, no. 4, pp. 840-845, 2006. 
[57] S. J. Chiu, J. I. Chao, Y. J. Lee, and T. S. Hsu, "Regulation of gamma-H2AX and securin contribute to apoptosis by oxaliplatin via a p38 mitogen-activated protein kinase-dependent pathway in human colorectal cancer cells," Toxicology Letters, vol. 179, no. 2, pp. 63-70, 2008.

[58] Y. Dong, M. Xiong, L. Duan et al., "H2AX phosphorylation regulated by p38 is involved in Bim expression and apoptosis in chronic myelogenous leukemia cells induced by imatinib," Apoptosis, vol. 19, no. 8, pp. 1281-1292, 2014.

[59] C. Lu, F. Zhu, Y. Y. Cho et al., "Cell apoptosis: requirement of $\mathrm{H} 2 \mathrm{AX}$ in DNA ladder formation, but not for the activation of caspase-3," Molecular Cell, vol. 23, no. 1, pp. 121-132, 2006.

[60] L. Galluzzi, I. Vitale, S. A. Aaronson et al., "Molecular mechanisms of cell death: recommendations of the Nomenclature Committee on Cell Death 2018," Cell Death \& Differentiation, vol. 25, no. 3, pp. 486-541, 2018.

[61] L. Bundscherer, K. Wende, K. Ottmuller et al., "Impact of non-thermal plasma treatment on MAPK signaling pathways of human immune cell lines," Immunobiology, vol. 218, no. 10, pp. 1248-1255, 2013.

[62] S. Bekeschus, J. Kolata, A. Muller et al., "Differential viability of eight human blood mononuclear cell subpopulations after plasma treatment," Plasma Medicine, vol. 3, no. 1-2, pp. 113, 2013.

[63] L. Bundscherer, S. Bekeschus, H. Tresp et al., "Viability of human blood leukocytes compared with their respective cell lines after plasma treatment," Plasma Medicine, vol. 3, no. 1-2, pp. 71-80, 2013.

[64] S. Bekeschus, K. Rödder, A. Schmidt et al., "Cold physical plasma selects for specific $\mathrm{T}$ helper cell subsets with distinct cells surface markers in a caspase-dependent and NF- $\kappa$ B-independent manner," Plasma Processes and Polymers, vol. 13, no. 12, pp. 1144-1150, 2016.

[65] P. S. Hole, J. Zabkiewicz, C. Munje et al., "Overproduction of NOX-derived ROS in AML promotes proliferation and is associated with defective oxidative stress signaling," Blood, vol. 122, no. 19, pp. 3322-3330, 2013.

[66] D. Slamenova, K. Kozics, L. Hunakova, M. Melusova, J. Navarova, and E. Horvathova, "Comparison of biological processes induced in HepG2 cells by tert-butyl hydroperoxide (t-BHP) and hydroperoxide $\left(\mathrm{H}_{2} \mathrm{O}_{2}\right)$ : the influence of carvacrol," Mutation Research/Genetic Toxicology and Environmental Mutagenesis, vol. 757, no. 1, pp. 15-22, 2013.

[67] N. M. Machado, A. B. Ribeiro, H. D. Nicolella et al., "Usnic acid attenuates genomic instability in Chinese hamster ovary $(\mathrm{CHO})$ cells as well as chemical-induced preneoplastic lesions in rat colon," Journal of Toxicology and Environmental Health, Part A, vol. 82, no. 6, pp. 401-410, 2019.

[68] J. Feruszova, P. Imreova, K. Bodnarova et al., "Photoactivated hypericin is not genotoxic," General physiology and biophysics, vol. 35, no. 02, pp. 223-230, 2016.

[69] K. Wende, S. Bekeschus, A. Schmidt et al., "Risk assessment of a cold argon plasma jet in respect to its mutagenicity," Mutation Research/Genetic Toxicology and Environmental Mutagenesis, vol. 798-799, pp. 48-54, 2016.

[70] V. Boxhammer, Y. F. Li, J. Koritzer et al., "Investigation of the mutagenic potential of cold atmospheric plasma at bactericidal dosages," Mutation Research/Genetic Toxicology and Environmental Mutagenesis, vol. 753, no. 1, pp. 23-28, 2013.

[71] T. Maisch, A. K. Bosserhoff, P. Unger et al., "Investigation of toxicity and mutagenicity of cold atmospheric argon plasma,"
Environmental and Molecular Mutagenesis, vol. 58, no. 3, pp. 172-177, 2017.

[72] S. Kluge, S. Bekeschus, C. Bender et al., "Investigating the mutagenicity of a cold argon-plasma jet in an HET-MN model," PLoS One, vol. 11, no. 9, 2016.

[73] S. Hasse, O. Hahn, S. Kindler, T. von Woedtke, H.R. Metelmann, and K. Masur, "Atmospheric pressure plasma jet application on human oral mucosa modulates tissue regeneration," Plasma Medicine, vol. 4, no. 1-4, pp. 117-129, 2014.

[74] A. Schmidt, T. Woedtke, J. Stenzel et al., "One year follow-up risk assessment in SKH-1 mice and wounds treated with an argon plasma jet," International Journal of Molecular Sciences, vol. 18, no. 4, p. 868, 2017.

[75] E. E. Farmer and M. J. Mueller, "ROS-mediated lipid peroxidation and RES-activated signaling," Annual Review of Plant Biology, vol. 64, no. 1, pp. 429-450, 2013.

[76] K. Kannan and S. K. Jain, "Effect of vitamin $B_{6}$ on oxygen radicals, mitochondrial membrane potential, and lipid peroxidation in $\mathrm{H}_{2} \mathrm{O}_{2}$-treated U937 monocytes," Free Radical Biology and Medicine, vol. 36, no. 4, pp. 423-428, 2004.

[77] G. Minotti and S. D. Aust, "The requirement for iron (III) in the initiation of lipid peroxidation by iron (II) and hydrogen peroxide," J Biol Chem, vol. 262, pp. 1098-1104, 1987.

[78] M. Iqbal, Y. Okazaki, and S. Okada, "In vitro curcumin modulates ferric nitrilotriacetate (Fe-NTA) and hydrogen peroxide $\left(\mathrm{H}_{2} \mathrm{O}_{2}\right)$-induced peroxidation of microsomal membrane lipids and DNA damage," Teratogenesis, Carcinogenesis, and Mutagenesis, vol. 23, no. S1, pp. 151-160, 2003.

[79] X. Zhang, X. F. Zhang, H. P. Li et al., "Atmospheric and room temperature plasma (ARTP) as a new powerful mutagenesis tool," Applied Microbiology and Biotechnology, vol. 98, no. 12, pp. 5387-5396, 2014.

[80] C. Ottenheim, M. Nawrath, and J. C. Wu, "Microbial mutagenesis by atmospheric and room-temperature plasma (ARTP): the latest development," Bioresources and Bioprocessing, vol. 5, no. 1, 2018.

[81] M. Fang, L. Jin, C. Zhang et al., "Rapid mutation of Spirulina platensis by a new mutagenesis system of atmospheric and room temperature plasmas (ARTP) and generation of a mutant library with diverse phenotypes," PLoS One, vol. 8, no. 10, p. e77046, 2013.

[82] X. Zhang, C. Zhang, Q. Q. Zhou et al., "Quantitative evaluation of DNA damage and mutation rate by atmospheric and roomtemperature plasma (ARTP) and conventional mutagenesis," Applied Microbiology and Biotechnology, vol. 99, no. 13, pp. 5639-5646, 2015.

[83] B. Zhao, Y. Li, C. Li, H. Yang, and W. Wang, "Enhancement of Schizochytrium DHA synthesis by plasma mutagenesis aided with malonic acid and zeocin screening," Applied Microbiology and Biotechnology, vol. 102, no. 5, pp. 2351-2361, 2018.

[84] W. Zeng, G. Du, J. Chen, J. Li, and J. Zhou, "A highthroughput screening procedure for enhancing $\alpha$-ketoglutaric acid production in Yarrowia lipolytica by random mutagenesis," Process Biochemistry, vol. 50, no. 10, pp. 1516-1522, 2015.

[85] F. Qi, Y. Kitahara, Z. Wang, X. Zhao, W. Du, and D. Liu, "Novel mutant strains ofRhodosporidium toruloidesby plasma mutagenesis approach and their tolerance for inhibitors in lignocellulosic hydrolyzate," Journal of Chemical Technology \& Biotechnology, vol. 89, no. 5, pp. 735-742, 2014.

[86] B. Liu, Z. Sun, X. Ma et al., "Mutation breeding of extracellular polysaccharide-producing microalga Crypthecodinium cohnii 
by a novel mutagenesis with atmospheric and room temperature plasma," International Journal of Molecular Sciences, vol. 16, no. 12, pp. 8201-8212, 2015.

[87] L. Zhu, D. Wu, H. Zhang et al., "Effects of atmospheric and room temperature plasma (ARTP) mutagenesis on physicochemical characteristics and immune activity in vitro of Hericium erinaceus polysaccharides," Molecules, vol. 24, no. 2, p. 262, 2019.

[88] X. Li, R. Liu, J. Li et al., "Enhanced arachidonic acid production from Mortierella alpina combining atmospheric and room temperature plasma (ARTP) and diethyl sulfate treatments," Bioresource Technology, vol. 177, pp. 134-140, 2015.

[89] X. Liu, J. Lv, J. Xu et al., "Erythritol production by Yarrowia lipolytica mutant strain M53 generated through atmospheric and room temperature plasma mutagenesis," Food Science and Biotechnology, vol. 26, no. 4, pp. 979-986, 2017.

[90] G. Cheng, J. Xu, X. Xia et al., "Breeding L-arginine-producing strains by a novel mutagenesis method: atmospheric and room temperature plasma (ARTP)," Preparative Biochemistry and Biotechnology, vol. 46, no. 5, pp. 509-516, 2016.

[91] Y. Ma, H. Yang, X. Chen et al., "Significantly improving the yield of recombinant proteins in Bacillus subtilis by a novel powerful mutagenesis tool (ARTP): Alkaline $\alpha$-amylase as a case study," Protein Expression and Purification, vol. 114, pp. 82-88, 2015.

[92] Y. Ma, W. Shen, X. Chen et al., "Significantly enhancing recombinant alkaline amylase production in Bacillus subtilis by integration of a novel mutagenesis-screening strategy with systems-level fermentation optimization," Journal of Biological Engineering, vol. 10, no. 1, 2016.

[93] J. Sun, Y. Wang, B. Wu, Z. Bai, and B. He, "Enhanced production of d-lactic acid by Sporolactobacillus sp.Y2-8 mutant generated by atmospheric and room temperature plasma," Biotechnology and Applied Biochemistry, vol. 62, no. 2, pp. 287-292, 2015.

[94] W. Qiang, F. Ling-ran, W. Luo et al., "Mutation breeding of lycopene-producing strain Blakeslea trispora by a novel atmospheric and room temperature plasma (ARTP)," Applied Biochemistry and Biotechnology, vol. 174, no. 1, pp. 452-460, 2014.

[95] C. Zhang, H. Shen, X. Zhang et al., "Combined mutagenesis of Rhodosporidium toruloides for improved production of carotenoids and lipids," Biotechnology Letters, vol. 38, no. 10, pp. 1733-1738, 2016.

[96] J. Winter, R. Brandenburg, and K. D. Weltmann, “Atmospheric pressure plasma jets: an overview of devices and new directions," Plasma Sources Science and Technology, vol. 24, no. 6, p. 064001, 2015.

[97] C. Ulrich, F. Kluschke, A. Patzelt et al., "Clinical use of cold atmospheric pressure argon plasma in chronic leg ulcers: a pilot study," Journal of Wound Care, vol. 24, no. 5, pp. 196203, 2015.

[98] M. Schuster, C. Seebauer, R. Rutkowski et al., "Visible tumor surface response to physical plasma and apoptotic cell kill in head and neck cancer," Journal of Cranio-Maxillofacial Surgery, vol. 44, no. 9, pp. 1445-1452, 2016.

[99] D. M. S. Pinto and A. Flaus, "Structure and function of histone H2AX," in Subcellular Biochemistry, vol. 50, Springer, Dordrecht, 2010. 


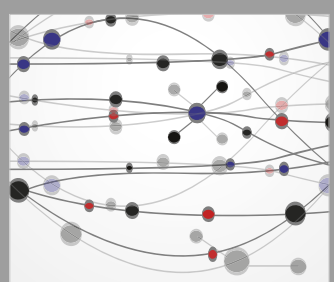

The Scientific World Journal
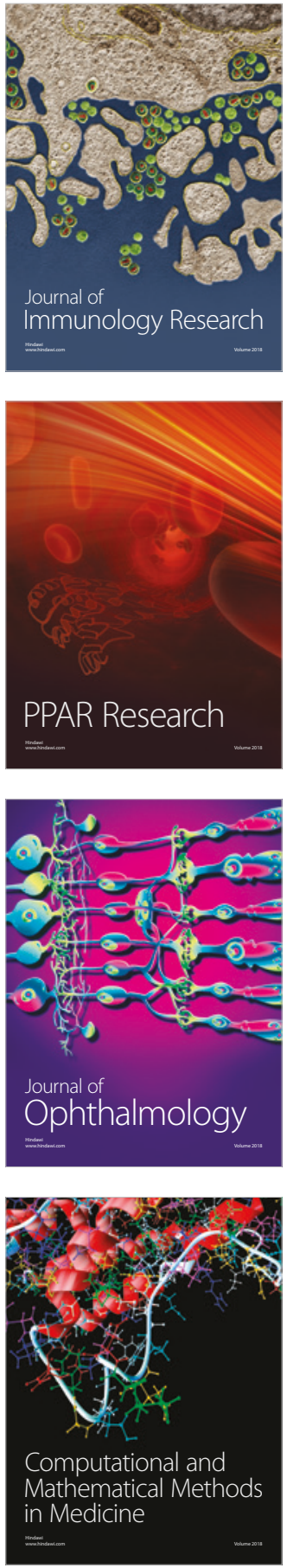

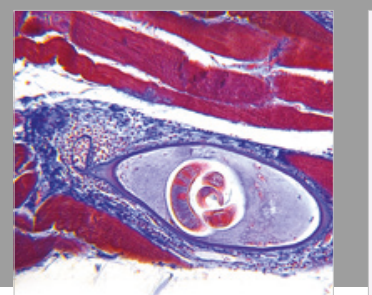

Gastroenterology Research and Practice

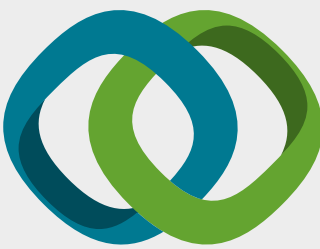

\section{Hindawi}

Submit your manuscripts at

www.hindawi.com
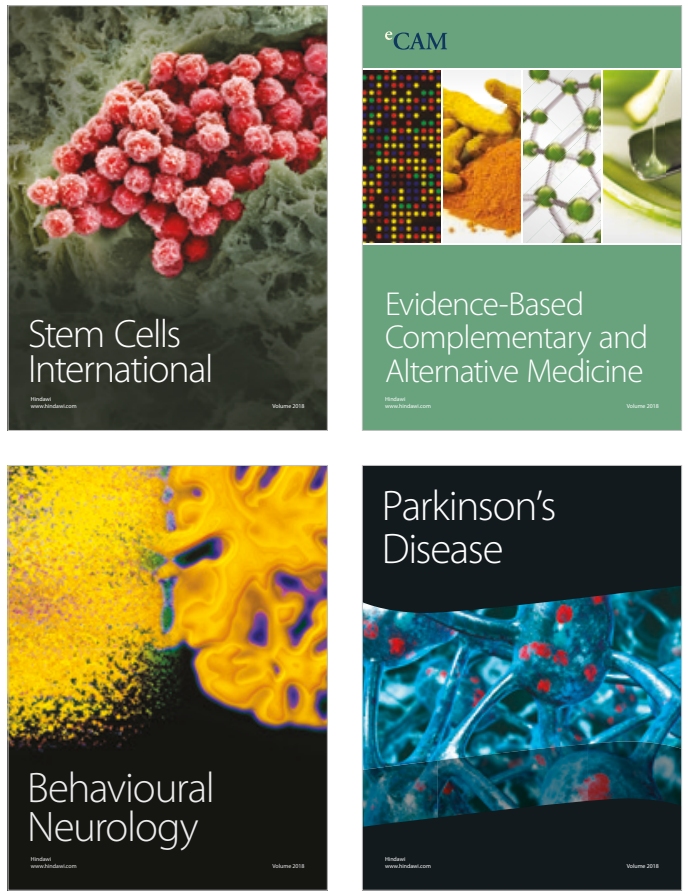

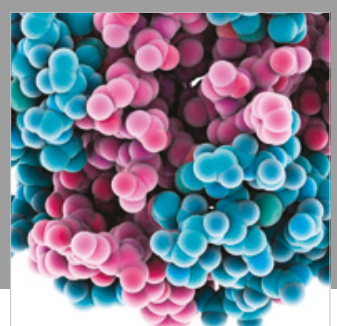

ournal of

Diabetes Research

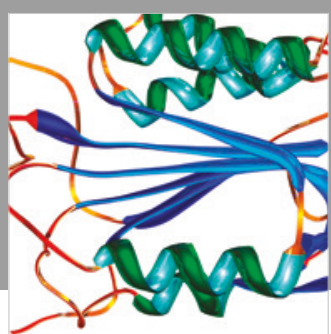

Disease Markers
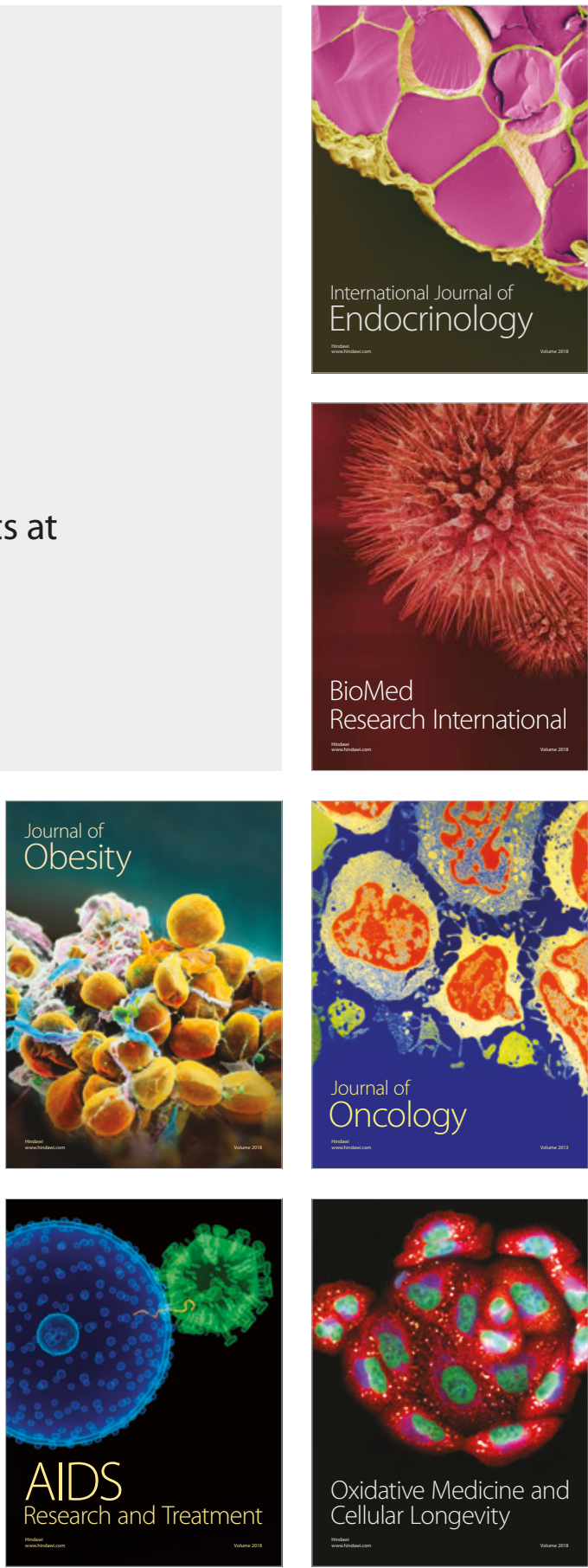